\title{
RMetS
}

Royal Meteorological Society

\section{Flow during the evening transition over steep Alpine slopes}

\author{
Daniel F. Nadeau, ${ }^{\mathrm{a}, \mathrm{b} \star}$ Eric R. Pardyjak, ${ }^{\mathrm{c}}$ Chad W. Higgins, ${ }^{\mathrm{a}, \mathrm{d}}$ Hendrik Huwald ${ }^{\mathrm{a}}$ and \\ Marc B. Parlange ${ }^{a}$ \\ ${ }^{a}$ School of Architecture, Civil and Environ. Engineering, École Polytechnique Fédérale de Lausanne, Switzerland \\ ${ }^{\mathrm{b}}$ Institut National de la Recherche Scientifique, Centre Eau, Terre et Environnement, Québec, Canada \\ ${ }^{\mathrm{c}}$ Department of Mechanical Engineering, University of Utah, Salt Lake City, UT, USA \\ ${ }^{\mathrm{d} D e p a r t m e n t ~ o f ~ B i o l o g i c a l ~ a n d ~ E c o l o g i c a l ~ E n g i n e e r i n g, ~ O r e g o n ~ S t a t e ~ U n i v e r s i t y, ~ C o r v a l l i s, ~ O R, ~ U S A ~}$
}

${ }^{*}$ Correspondence to: D. F. Nadeau, School of Architecture, Civil and Environmental Engineering, Station 2, Bâtiment GR, EPFL-EFLUM, Lausanne 1015, Switzerland. E-mail: daniel.nadeau.1@gmail.com

\begin{abstract}
A field campaign, the Slope Experiment near La Fouly (SELF-2010), was conducted to monitor the evening transition of slope flows on clear-sky days from July to September 2010 in a narrow valley of the Swiss Alps. A steep west-facing slope with inclinations ranging from $25^{\circ}$ to $45^{\circ}$ was instrumented from $1900 \mathrm{~m}$ to $2200 \mathrm{~m}$ above sea-level. Detailed measurements were made along a linear transect of the slope with two turbulence towers, two weather stations, five surface temperature measurement stations and a tethered balloon system. The present study focuses on nine exemplary 'convective' days, characterized by weak synoptic flow and clear-sky conditions, during which thermal circulations prevail. The analysis of the observational data shows that topographic shading triggers the evening transition. The topographic configuration around the experimental site results in a sharply defined 'shading front' propagating upslope, causing a sudden decrease in incoming short-wave radiation on the order of several hundreds of $\mathrm{W} \mathrm{m}^{-2}$ within a few minutes. The slope surface rapidly responds to the advancing shading front; in some cases, reductions in surface temperatures of some $10^{\circ} \mathrm{C}$ in less than $10 \mathrm{~min}$ are observed. This is rapidly followed by an early-evening calm period with very small turbulent kinetic energy $\left(\mathrm{TKE}<0.05 \mathrm{~m}^{2} \mathrm{~s}^{-2}\right.$ ) and extremely light wind speeds $\left(<0.5 \mathrm{~m} \mathrm{~s}^{-1}\right)$. When the inertia-driven upslope flow is fully stopped by the katabatic acceleration, a shallow local drainage flow forms and reaches a quasi-equilibrium $1.5 \mathrm{~h}$ after the local sunset. An analysis of the TKE budget close to the surface shows that the buoyancy flux is much greater than the shear production in the last hours before the local sunset, possibly due to valley curvature effects. Copyright (c) 2012 Royal Meteorological Society
\end{abstract}

Key Words: eddy covariance; decay of turbulence; directional planar fit; katabatic winds; topographic shading; turbulent kinetic energy

Received 26 August 2011; Revised 5 March 2012; Accepted 2 May 2012; Published online in Wiley Online Library 3 July 2012

Citation: Nadeau DF, Pardyjak ER, Higgins CW, Huwald H, Parlange MB. 2013. Flow during the evening transition over steep Alpine slopes. Q. J. R. Meteorol. Soc. 139: 607-624. DOI:10.1002/qj.1985

1. Introduction

On a clear-sky day with weak synoptic forcing, thermally induced circulations following a diurnal cycle prevail in Alpine valleys. In a shallow layer close to the valley sidewalls (depth 10-100 m; Whiteman, 2000), winds typically travel upslope during the day (anabatic flow) and downslope at night (katabatic or drainage flow). These slope flows are driven by horizontal temperature gradients between air above heated/cooled inclined surfaces and air located in 
the centre of the valley. Above the slope flow layer, a more powerful along-valley circulation is usually found, with upvalley winds during the day and downvalley flow at night. On evenings of 'convective' days, characterized by weak winds aloft and sunny conditions, turbulent upslope flow is replaced by statically stable downslope motions. The dynamics of this unsteady transition period have important implications for the transport of water vapour, fresh air and pollutants, and an understanding of these processes is required for accurate atmospheric, hydrologic and dispersion modelling.

The evening transition period in the atmospheric boundary layer $(\mathrm{ABL})$ has received considerable attention in past years. Efforts to understand the flow phenomena have included large-eddy simulations (Sorbjan, 1997; Pino et al., 2006), theoretical analyses (Goulart et al., 2003; Nadeau et al., 2011), laboratory work (Cole and Fernando, 1998) and field studies (Grant, 1997; Acevedo and Fitzjarrald, 2001). Nearly all of these studies were limited to flat surfaces, thus most findings may not apply to transitions of slope flows.

Most descriptions of slope flows have focused on (quasi-) steady-state conditions (e.g. Kondo and Sato, 1988; Shapiro and Fedorovich, 2007; Princevac et al., 2008). However, Hunt et al. (2003) developed a model specifically for the evening transition period of slope flows, in which downslope motions are preceded by a 'transition front' propagating downslope. Their analysis was elaborated for gentle slopes in wide valleys with $L \sim 5-15 \mathrm{~km}$, where $L$ is the slope length-scale. Observations from a laboratory experiment highlighted important surface convergence and mixing in the vicinity of the transition front. Brazel et al. (2005) and Pardyjak et al. (2009) later confirmed the existence of the transition front with field observations over a very gentle $\left(1^{\circ}\right)$ slope, but little is known about the applicability of the model of Hunt et al. (2003) in steep and narrow Alpine valleys.

Major field studies focusing on the ABL dynamics over mountainous terrain include the Transport of Air Pollutants over Complex Terrain (TRACT) field campaign over the German Hornisgrinde mountains (Kossmann et al., 1998), the Mesoscale Alpine Program (MAP)-Riviera Experiment over the Southern Swiss Alps (Rotach et al., 2004), the Terrain-induced Rotor Experiment (T-REX) over the Sierra Nevada mountain range in California (Grubisic et al., 2008) and the Meteor Crater Experiment (METCRAX) within and around Meteor Crater in Arizona (Whiteman et al., 2008). Mountain flows were also carefully studied by Whiteman and Doran (1993) in the Tennessee Valley, who showed that thermal circulations prevailed only when large-scale pressure-driven channelling and downward momentum transfer of upper-level flow were negligible.

A few field studies have precisely addressed slope flow transitions. Papadopoulos and Helmis (1999) conducted an experiment on an isolated slope in Greece and looked at the onset and destruction of katabatic flow by comparing terms in the momentum and energy equations. Papadopoulos and Helmis proposed making a distinction between katabatic flows generated by local surface radiative cooling and those generated from subsiding cold air from aloft. More recently, Mahrt et al. (2010) studied the interactions between downslope flows and the nocturnal cold air pool forming on a valley floor. They report on an 'early evening calm' period occasionally preceding the onset of drainage flow, with very light winds and variable wind directions.
Several numerical studies have investigated upslope flows (Schumann, 1990; Serafin and Zardi, 2010a,b), downslope flows (Skyllingstad, 2003; Smith and Skyllingstad, 2005; Trachte et al., 2010), but rarely both together (Fedorovich and Shapiro, 2009). Moreover, very few numerical analyses have described the dynamics of slope flows during transition periods. Colette et al. (2003) highlighted the role of topographic shading on the morning break-up of the nocturnal surface inversion. Catalano and Cenedese (2010) did model a full $24 \mathrm{~h}$ cycle of atmospheric flow over a slope. Using the Weather Research and Forecasting (WRF) model in large-eddy simulation mode, they found that the topographic amplification factor was a key parameter in the onset of drainage flow as it controlled the development of the stable boundary layer. The topographic amplification factor, also referred to as the valley volume effect, implies that, for the same radiative input and top cross-section, smaller air volumes in valleys than over flat terrain result in greater temperature changes (Whiteman, 1990).

Current numerical models tend to suffer from limitations when they model slope flow over steep terrain. To capture the small-scale physics occurring close to the surface, modellers commonly use a vertically compressed grid, but it has the drawback of generating grid anisotropy (thus numerical instability) in that region. Large aspect ratios of grid cells are also found when terrain-following coordinates are used over steep slopes, which is the case for many mesoscale models. Most numerical models also tend to underestimate turbulence intensity in very stable boundary layers, as a result of an overestimated surface cooling (Mahrt, 1998). This so-called 'run-away' cooling is particularly problematic when modelling thermally driven circulations such as slope flows.

In this study, we deployed several meteorological stations along a transect of a steep mountain slope $\left(25^{\circ}\right.$ to $\left.45^{\circ}\right)$ in the Swiss Alps during summer 2010, measuring a suite of atmospheric variables such as radiative and turbulent fluxes. The main objective was to capture the complex interplay between the slope surface and the atmosphere during the evening solar forcing transition period on convective days. The paper follows the sequence of events taking place on the evening of convective days, highlighting the important role of topographic shading in the destruction and onset of slope flows. First, the radiation balance is described, followed by the surface and near-surface responses. Vertical atmospheric profiles are presented with particular attention to the flow reversal close to the surface. The onset of a drainage flow is described in the context of the governing equations of motion, and finally the turbulent kinetic energy budget is analysed.

\section{Methods}

\subsection{Study area}

During the Slope Experiment near La Fouly (SELF-2010), a west-facing slope located in a narrow Alpine valley of the southwestern Swiss Alps was instrumented from early July to the end of September 2010. The experimental site $\left(45^{\circ} 54^{\prime} 7^{\prime \prime} \mathrm{N}, 7^{\circ} 7^{\prime} 24^{\prime \prime} \mathrm{E}\right)$ is on the Swiss border with Italy close to France (Figure 1(a)). The valley geometry is complex, and representative of most Alpine valleys in the area. The main valley runs along a northwest-southeast axis, but around the site it is curved and displays a north-south axis 

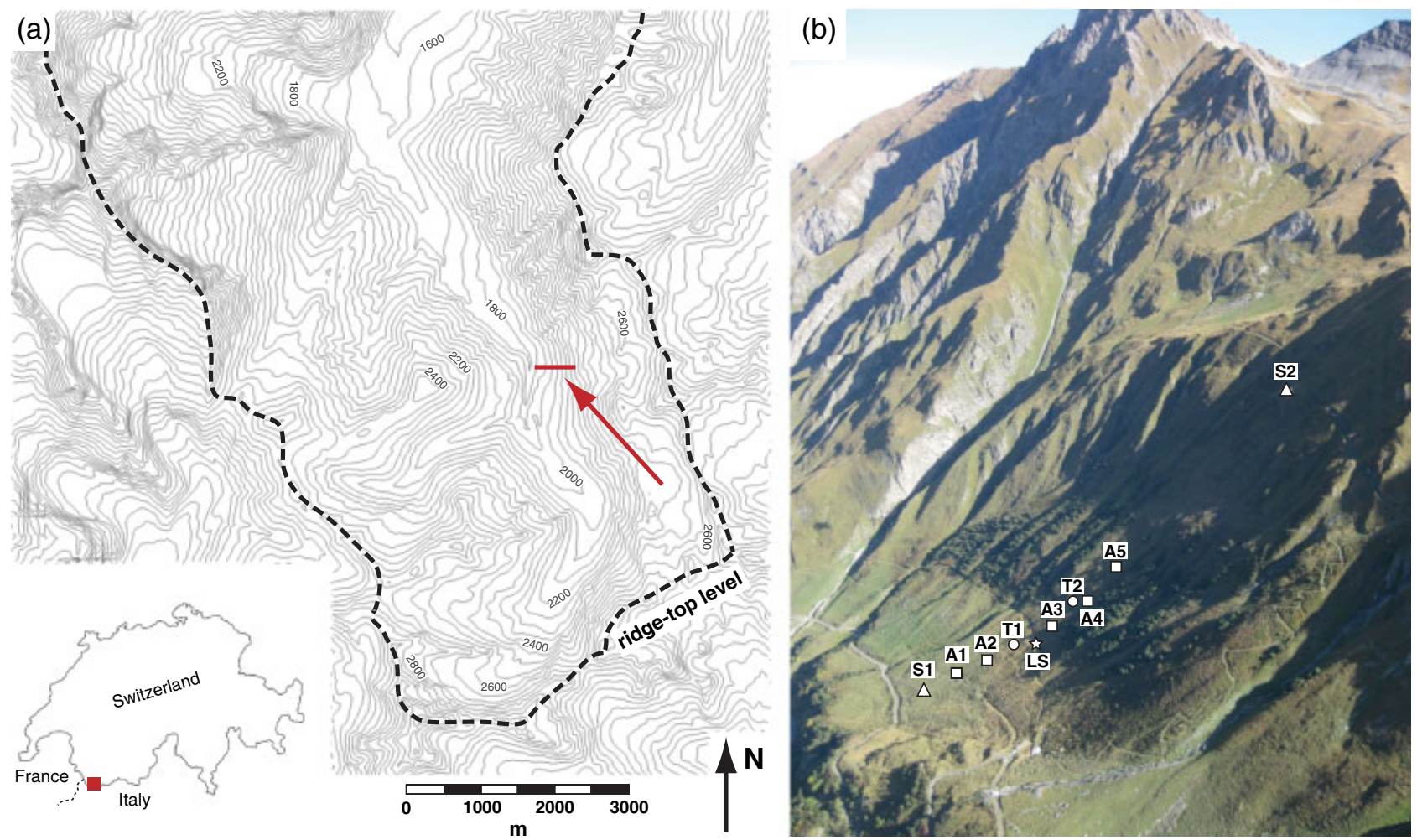

Figure 1. (a) Topographic map showing the experimental set-up (a transect between 1897 and $2200 \mathrm{~m}$ asl) in red, and the location of the experimental site, Val Ferret, in Switzerland. The contour interval is $50 \mathrm{~m}$. (b) Photograph of the slope around morning transition on 21 September 2010 with the experimental layout. Labels are explained in section 2.2.

(thus, the instrumented slope is facing west) for a small segment (Figure 1(b)). Note that there is a 'side valley' (axis east-west), which joins the main valley in the vicinity of the experimental site.

The slope was selected because of the absence of major topographic discontinuities for a $700 \mathrm{~m}$ long segment between altitudes of 1850 to $2350 \mathrm{~m}$ above sea level (asl) (Figure 2), where the surface is relatively uniform. Along the instrumented part of the slope, the inclinations vary from $25^{\circ}$ to $45^{\circ}$. In summer, the lower part of the slope (below site LS, Figure 1) serves as a pasture. The valley floor is located at $1800 \mathrm{~m}$ asl and is flanked by a steep $50 \mathrm{~m}$ high river escarpment. To the east of the experimental site, the ridge-top level is approximately $2800 \mathrm{~m}$ asl, and on the west side it is roughly $2600 \mathrm{~m}$ asl. Various shallow gullies occupy the valley hillsides. Apart from $30 \mathrm{~cm}$ grass, 3-4 m tall shrubs are found on both sides of the experimental transect, but far enough from the instrumentation so that their influence can be neglected. The surface roughness found from the analysis of experimental data is approximately $0.15 \mathrm{~m}$.

The air temperature throughout the campaign varied between -2 and $23^{\circ} \mathrm{C}$, with an average of $11^{\circ} \mathrm{C}$. As a result of shading from the surrounding terrain, on clearsky days the slope was generally exposed to direct sunlight from $3.5 \mathrm{~h}$ after the astronomical sunrise to $1.5 \mathrm{~h}$ before the astronomical sunset. The local cumulative rainfall for the experimental period reached $310 \mathrm{~mm}$, and the mean daytime Bowen ratio on clear-sky days was 0.6.

\subsection{Instrumentation}

The meteorological equipment deployed along the slope (Figures 1(b) and 2) consisted of: (i) a single-level turbulence and radiation tower, $\mathrm{T} 1$;

(ii) a multi-level $10 \mathrm{~m}$ turbulence tower, T2;

(iii) two wireless weather stations, S1 and S2;

(iv) five thermal infrared sensing stations, A1 to A5.

The location and elevation of each site is presented in Table 1. The sensor configurations for the two towers (T1 and T2) are described in Figure 3 and Table 2.

(i) The surface energy budget tower was installed in the lower part of the slope transect, at $1939 \mathrm{~m}$ asl, where the slope inclination is $30^{\circ}$. The station was equipped with two sonic anemometers (same level, opposite directions), one open-path infrared fast-response $\mathrm{CO}_{2}-\mathrm{H}_{2} \mathrm{O}$ analyser, four radiometers mounted parallel to the slope to measure all components of the radiation balance, soil heat flux plates and traditional meteorological sensors measuring air temperature and relative humidity, surface temperature, precipitation, wind speed and wind direction (Table 2).

(ii) The $10 \mathrm{~m}$ mast, installed slightly higher on the slope at $1988 \mathrm{~m}$ asl, was equipped with four three-dimensional sonic anemometers as well as two air temperature and relative humidity probes at different heights (Table 2 ). The slope inclination at this location is $41^{\circ}$. The second lowest sonic had to be excluded from the analysis due to a calibration issue.

(iii) The two wireless weather stations, relying on Sensorscope technology (Nadeau et al., 2009; Ingelrest et al., 2010), were part of a sensor network of 15 similar stations monitoring catchment-scale meteorological and hydrological processes (Simoni et al., 2011). Each station was equipped with several meteorological 


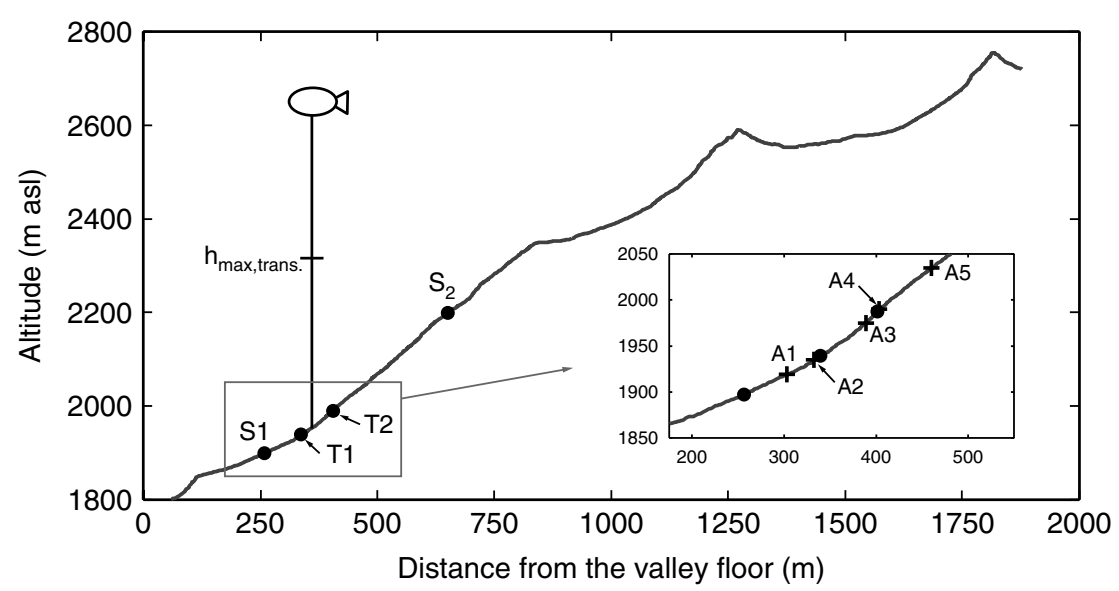

Figure 2. Slope transect as a function of distance from the valley floor. The axes have the same scale to show actual slopes. $h_{\text {max,trans }}$ denotes the maximum height attained with the tethered balloon system during transition periods. The position of the thermal infrared sensing stations is shown in the lower right corner. The slope transect was extracted from a $1 \mathrm{~m}$ digital elevation model of the area.

Table 1. Station details.

\begin{tabular}{|c|c|c|c|c|c|}
\hline Station & $\begin{array}{l}\text { Latitude } \\
\text { (N) }\end{array}$ & $\begin{array}{l}\text { Longitude } \\
\text { (E) }\end{array}$ & $\begin{array}{l}\text { Elevation } \\
(\mathrm{m} \text { asl })\end{array}$ & $\begin{array}{c}\text { Inclination } \\
\left({ }^{\circ}\right)\end{array}$ & Measurement system \\
\hline $\mathrm{S} 1$ & $45^{\circ} 54^{\prime} 8^{\prime \prime}$ & $7^{\circ} 7^{\prime} 19^{\prime \prime}$ & 1897 & 25 & met, soil \\
\hline A1 & $45^{\circ} 54^{\prime} 7^{\prime \prime}$ & $7^{\circ} 7^{\prime} 21^{\prime \prime}$ & 1920 & 26 & tir \\
\hline $\mathrm{A} 2$ & $45^{\circ} 54^{\prime} 7^{\prime \prime}$ & $7^{\circ} 7^{\prime} 22^{\prime \prime}$ & 1935 & 28 & tir \\
\hline $\mathrm{T} 1$ & $45^{\circ} 54^{\prime} 7^{\prime \prime}$ & $7^{\circ} 7^{\prime} 23^{\prime \prime}$ & 1939 & 30 & met, rad, turb, soil \\
\hline LS & $45^{\circ} 54^{\prime} 6^{\prime \prime}$ & $7^{\circ} 7^{\prime} 24^{\prime \prime}$ & 1950 & 32 & bal \\
\hline A3 & $45^{\circ} 54^{\prime} 7^{\prime \prime}$ & $7^{\circ} 7^{\prime} 25^{\prime \prime}$ & 1975 & 37 & tir \\
\hline $\mathrm{T} 2$ & $45^{\circ} 54^{\prime} 7^{\prime \prime}$ & $7^{\circ} 7^{\prime} 26^{\prime \prime}$ & 1988 & 41 & turb, met \\
\hline $\mathrm{A} 4$ & $45^{\circ} 54^{\prime} 7^{\prime \prime}$ & $7^{\circ} 7^{\prime} 26^{\prime \prime}$ & 1990 & 41 & tir \\
\hline A5 & $45^{\circ} 54^{\prime} 7^{\prime \prime}$ & $7^{\circ} 7^{\prime} 29^{\prime \prime}$ & 2035 & 39 & tir \\
\hline $\mathrm{S} 2$ & $45^{\circ} 54^{\prime} 8^{\prime \prime}$ & $7^{\circ} 7^{\prime} 37^{\prime \prime}$ & 2200 & 39 & met, soil \\
\hline
\end{tabular}

bal = tethersonde balloon; met = meteorological slow-response sensors; rad = radiometers; soil = soil measurements; tir = thermal infrared skin temperature sensors; turb = fast-response turbulence sensors.

sensors, but in this study only wind speed and direction were used (Davis Instrument Model 7911, mounted at $1.5 \mathrm{~m}$ above the surface, accuracy: $\pm 1 \mathrm{~m} \mathrm{~s}^{-1}, \pm 7^{\circ}$ ).

(iv) The five low-cost thermal infrared sensors (Zytemp TN901 infrared thermometers, accuracy: $\pm 0.6{ }^{\circ} \mathrm{C}$ ) were deployed between elevations 1920 and $2035 \mathrm{~m}$. The sensors, connected to Arduino boards (http://arduino.cc/en/), were installed at $1.2 \mathrm{~m}$ above the surface. Most of these sensors suffered from technical problems resulting in discontinuous data.

The sonic anemometers and the gas analyser were sampled at $10 \mathrm{~Hz}$, and all other sensors were sampled at $0.1 \mathrm{~Hz}$. The measurements were acquired with two CR5000 (Campbell Scientific) data loggers. Most of the ground-based stations were operational from the end of July to the end of September.

The ground-based measurements were accompanied by atmospheric profiling with a tethersonde system during three $24 \mathrm{~h}$ intensive observation periods characterized by weak synoptic activity and clear-sky conditions. A TTS 111 tethersonde (Vaisala) attached to a heliumfilled $9 \mathrm{~m}^{3}$ balloon was used to obtain vertical profiles of air temperature, relative humidity, wind speed and wind direction, with respective accuracies of $0.5^{\circ} \mathrm{C}, 5 \%$, $0.5 \mathrm{~m} \mathrm{~s}^{-1}$ and approximately $10^{\circ}$. Measurements were radio-transmitted by the sonde approximately every two seconds to a sounding processor (SPS220T, Vaisala). The tethersonde launching site (LS, Figure 1(b)) was located along the experimental transect, at an elevation of $1950 \mathrm{~m}$ asl. Daytime and night-time soundings were collected up to $700 \mathrm{~m}$ above the surface, whereas soundings during the morning and evening transitions were limited to a $400 \mathrm{~m}$ layer above the ground (Figure 2). The objective was to increase the frequency of soundings during periods with a rapidly evolving atmospheric structure. In all cases, the ascent/descent rate was $\approx 0.3 \mathrm{~m} \mathrm{~s}^{-1}$.

\subsection{Sensor orientation}

Over sloping terrain, the orientation of certain sensors relative to the underlying surface is an important issue. For instance, a cup anemometer must be mounted vertically for the ball bearings to work optimally and yield accurate measurements. The cups are also specifically designed to sample horizontal winds. Thus this type of sensor captures only a fraction of the total 3D wind velocity, assuming that the flow is approximately parallel to the slope. Sonic anemometers are more flexible in that sense, given the a posteriori tilt corrections that can be used to adjust the frame of reference with respect to the flow. As discussed in Geissbuhler et al. (2000), over steep slopes sonic anemometers should be mounted in a slope-normal configuration (e.g. as in the study of Van Gorsel et al., 2003). Indeed, according to a wind tunnel experiment by Christen 
Table 2. Instrumentation deployed at stations $\mathrm{T} 1$ and $\mathrm{T} 2$. The measurement heights shown are along a vertical frame of reference $\left(z_{\text {vert }}\right)$ and also normal to the surface $\left(z_{\text {norm }}\right)$. Measurement accuracies provided by the manufacturers are reported, when available.

\begin{tabular}{|c|c|c|c|c|c|c|}
\hline Station & $\begin{array}{l}\text { Label in } \\
\text { Figure } 3\end{array}$ & $\begin{array}{l}\text { Variables } \\
\text { measured }\end{array}$ & Accuracy & $z_{\text {vert }}(\mathrm{m})$ & $z_{\text {norm }}(\mathrm{m})$ & Instrument type \\
\hline \multirow[t]{11}{*}{$\mathrm{T} 1$} & A & $|u|$ & $\pm 0.1 \mathrm{~m} \mathrm{~s}^{-1}$ & 3.1 & 2.7 & Vector Inst. A100R \\
\hline & B & $\phi$ & $\pm 2^{\circ}$ & 2.7 & 2.3 & Vector Inst. W200P \\
\hline & $\mathrm{C}$ & $u, v$ & $\pm 0.04 \mathrm{~m} \mathrm{~s}^{-1}$ & 2.3 & 2.0 & Campbell Sci. CSAT3 \\
\hline & & $w$ & $\pm 0.02 \mathrm{~m} \mathrm{~s}^{-1}$ & & & \\
\hline & & $T_{\mathrm{v}}$ & $\mathrm{n} / \mathrm{a}$ & & & \\
\hline & & {$\left[\mathrm{H}_{2} \mathrm{O}\right],\left[\mathrm{CO}_{2}\right]$} & $\mathrm{n} / \mathrm{a}$ & 2.3 & 2.0 & Licor 7500 \\
\hline & $\mathrm{D}$ & $R H, T_{\mathrm{a}}$ & $\pm 2 \%, \pm 0.2^{\circ} \mathrm{C}$ & 2.1 & 1.8 & Rotronic MP100 \\
\hline & $\mathrm{E}$ & $u, v, w, T_{\mathrm{v}}$ & (as T1-C) & 2.9 & 2.5 & Campbell Sci. CSAT3 \\
\hline & $\mathrm{F}$ & $K \downarrow, K \uparrow$ & $\mathrm{n} / \mathrm{a}$ & $2.4,2.1$ & $2.1,1.8$ & Kipp \& Zonen CM21 \\
\hline & & $L \downarrow, L \uparrow$ & $\mathrm{n} / \mathrm{a}$ & $2.4,2.1$ & $2.1,1.8$ & Kipp \& Zonen CG4 \\
\hline & G & $T_{\mathrm{s}}$ & $\pm 0.3^{\circ} \mathrm{C}$ & 1.8 & 1.6 & Apogee Precision IRTS-P \\
\hline \multirow[t]{6}{*}{$\mathrm{T} 2$} & A & $u, v, w, T_{\mathrm{v}}$ & (as T1-C) & 2.0 & 1.5 & Campbell Sci. CSAT3 \\
\hline & B & $R H, T_{\mathrm{a}}$ & $\pm 2 \%, \pm 0.2^{\circ} \mathrm{C}$ & 2.4 & 1.8 & Vaisala HMP45C \\
\hline & $\mathrm{C}$ & $u, v, w, T_{\mathrm{v}}$ & (as T1-C) & 4.8 & 3.6 & Campbell Sci. CSAT3 \\
\hline & $\mathrm{D}$ & $R H, T_{\mathrm{a}}$ & (as T2-B) & 5.6 & 4.2 & Vaisala HMP45C \\
\hline & $\mathrm{E}$ & $u, v, w, T_{\mathrm{v}}$ & (as T1-C) & 6.2 & 4.7 & Campbell Sci. CSAT3 \\
\hline & $\mathrm{F}$ & $u, v, w, T_{\mathrm{v}}$ & (as $\mathrm{T} 1-\mathrm{C}$ ) & 7.8 & 5.9 & Campbell Sci. CSAT3 \\
\hline
\end{tabular}

$u, v, w$ are the three components of the wind speed, $|u|$ is the magnitude of the horizontal wind speed, and $\phi$ is the horizontal wind direction. $R H$ is the relative humidity.

$T_{\mathrm{v}}$ is the virtual air temperature, $T_{\mathrm{a}}$ is the air temperature, and $T_{\mathrm{s}}$ is the surface temperature.

$K \downarrow$ is the incoming short-wave radiation, $K \uparrow$ is the outgoing short-wave radiation,

$L \downarrow$ is the incoming long-wave radiation, and $L \uparrow$ is the outgoing long-wave radiation.
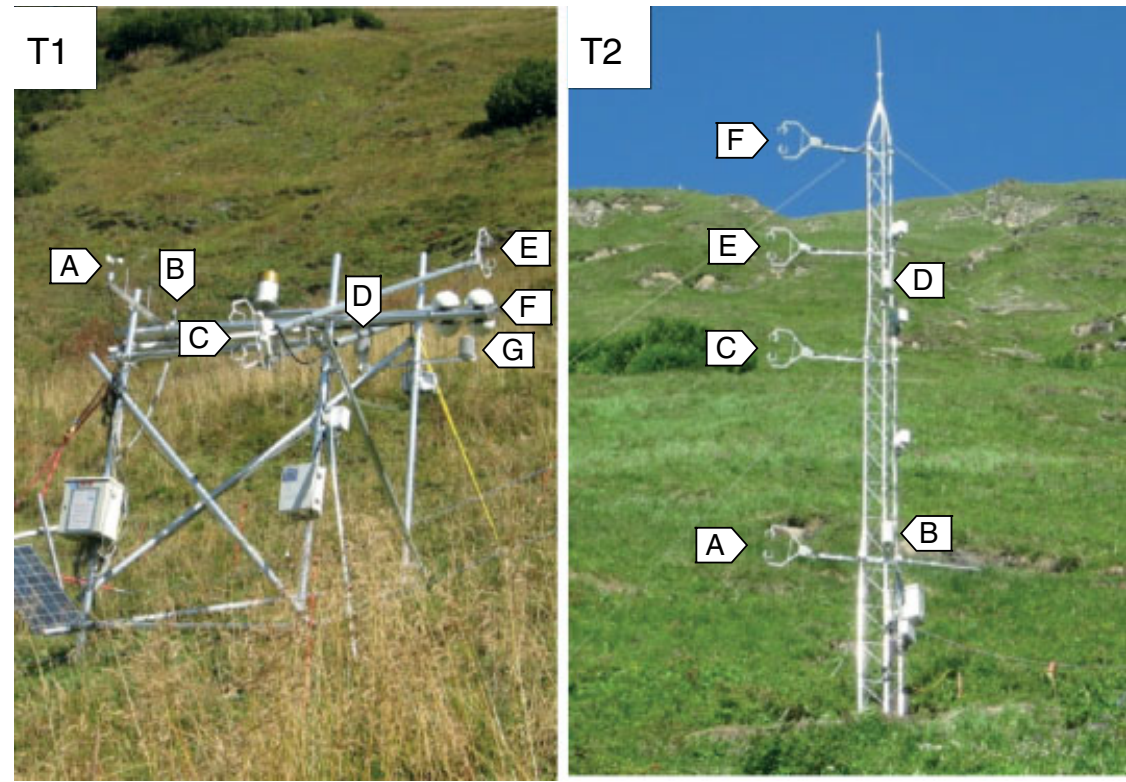

Figure 3. (a) Photograph of the surface energy budget tower (T1). (b) Photograph of the $10 \mathrm{~m}$ turbulence mast (T2).

et al. (2001), beyond an angle of incidence of $\pm 10^{\circ}$, the flow distortion induced by the ultrasonic transducers becomes non-negligible. The sonic anemometers are also usually more accurate along the $z$-direction. In a similar manner, radiometers should be mounted parallel to the inclined surface to accurately measure radiative fluxes normal to the sloped plane without having to correct for terrain effects (Whiteman et al., 1989; Matzinger et al., 2003; Hoch and Whiteman, 2010). Hence, for this experiment the sonic anemometers and radiation sensors were oriented such that the axis typically taken as the vertical axis over flat terrain was oriented normal to the local slope. Sensor corrections are described in the following section.

\subsection{Data processing}

Turbulent fluxes of heat and momentum were determined using the eddy covariance (EC) technique. This approach is traditionally considered most accurate over flat and homogeneous surfaces and for stationary flows (Baldocchi, 2003). Recently, some field studies have successfully used EC over mountainous terrain (Van Gorsel et al., 2003; Rotach et al., 2004; Hammerle et al., 2007; Lewis et al., 2008; Etzold et al., 2010). Hiller et al. (2008), for instance, explored the validity of the EC method over complex Alpine terrain and found that high-quality flux measurements were possible over such challenging locations. Additionally, Rotach and Zardi (2007) found that boundary-layer scaling could hold 
even over highly complex Alpine terrain, if the appropriate scaling variables are selected.

The analysis of transition periods with the EC technique is difficult due to the unsteadiness of the flow. Traditionally, this period of the day is excluded from analyses as it tends to fail the stationarity test described in Foken and Wichura (1996). Some studies have used EC measurements to investigate diurnal transition periods in the past (Angevine et al., 2001; Pardyjak et al., 2009), and most of the important issues are adequately addressed if a proper averaging period for the calculation of turbulent fluxes is selected. To do so, a balance has to be found between capturing flux contribution from large eddies (long averaging periods) and relevant flow non-stationarities (small averaging periods). These flow non-stationarities depend to a large extent on the reaction time of slope winds to changes in forcing. Kossmann and Fiedler (2000) have found those to be very small (30 to 120 s). Major flow non-stationarities are expected during the evening transition stage, during which turbulence levels can become very weak (Nieuwstadt and Brost, 1986), and the time-scales of turbulent transport very small $(<10 \mathrm{~s})$ (Mahrt and Vickers, 2006). A risk of using a long averaging period during the evening transition could be to accidentally include large-scale motions not relevant to turbulence and lead to significant errors in the resulting turbulent flux (Mahrt and Vickers, 2006). In view of these issues, we computed 'ogive' functions (Oncley et al., 1996, give a good example) for a sample convective day (not shown) and concluded that averaging periods of 5 min represented the best compromise.

Prior to time averaging, the turbulence data were rotated into a streamline coordinate system with the planar fit approach (Wilczak et al., 2001), which traditionally consists of a long-term regression (in our case segments of a few weeks) of the horizontal wind velocities to obtain a zero mean vertical velocity. Finnigan et al. (2003) have shown that the theoretical basis behind this correction is more robust than the 'traditional' double rotation for flow over complex terrain. The planar fit method has also been successfully used in several studies dealing with atmospheric flow over steep slopes (Hammerle et al., 2007; Kleissl et al., 2007; Rotach and Zardi, 2007). In this study, we used a 'directional' planar fit correction, in which a long-term regression of horizontal winds was performed independently over four different wind sectors. Rotach et al. (2008) highlighted that this method would minimize the uncertainty of wind velocities normal to the surface, and allow for better estimates of the advective fluxes found over complex terrain.

In our analysis, when calculating simple statistics of the key variables, the median rather than the mean is used since it is less affected by occasional extreme values. Otherwise, sample representative days are presented to illustrate the significant physical mechanisms occurring during the transition period. Unless specified, all heights are reported normal to the surface. Central European Time $(\mathrm{CET}, \mathrm{UTC}+1)$ is used throughout the study.

\section{Results and discussion}

The results presented here focus on thermally induced circulations that develop on 'convective' days with weak synoptic pressure gradients and clear-sky conditions. Based on the incoming short-wave radiation data, we selected nine convective days, namely 31 July, 7, 9 and 21 August, 1, 3,
11, 19 and 20 September 2010. On these days, the frequency distribution of wind directions near the surface was bimodal (not shown), with daytime winds oriented upvalley and night-time winds oriented downslope. Whiteman (2000) shows that diurnal mountain winds are typically organized into a shallow layer of weak slope flow (depth $\sim 10-100 \mathrm{~m}$, $u \sim 1-5 \mathrm{~m} \mathrm{~s}^{-1}$ ) overlaid by a more powerful along-valley flow layer occupying the rest of the valley airshed. In our case, during the day, the turbulent convective eddies tend to mix these two layers and upvalley winds are observed near the surface. These winds contain an upslope component due to the curvature of the valley axis near the experimental site. At night, stable stratification limits the vertical exchanges between the slope flow and the along-valley winds, thus near-surface winds follow the line of steepest descent and downslope flow is usually measured at our site.

\subsection{Evolution of the radiation budget}

The complex spatial distribution of radiation in mountainous terrain is known to determine to a large extent the behaviour of turbulent exchanges between the surface and the atmosphere (e.g. Matzinger et al., 2003). Some field studies have focused on radiative fluxes in mountainous terrain (Whiteman et al., 1989; Matzinger et al., 2003; Oliphant et al., 2003; Hoch and Whiteman, 2010), but little is known about their influence on thermally induced winds. Note that, as a result of topographic shading at the experimental site, the astronomical sunset, which is when the upper edge of the solar 'disk' disappears below the horizon of a perfectly flat ground plane, differs from the local sunset, which is the time when the direct incoming solar radiation goes to zero on the slope.

The surface radiation budget is given by

$$
R_{\mathrm{n}}=K \downarrow+K \uparrow+L \downarrow+L \uparrow,
$$

where the four components of the net radiation, $R_{\mathrm{n}}$, are the incoming short-wave $K \downarrow$, the reflected short-wave $K \uparrow$, the incoming long-wave $L \downarrow$ and the outgoing long-wave $L \uparrow$ radiation. The sign convention is such that incoming fluxes are positive and outgoing fluxes are negative.

Figure 4 illustrates the radiative components of (1) for four out of the nine convective days. The theoretical incoming short-wave radiation is also shown for a flat unobstructed surface at the same latitude. To calculate this, we estimated the extraterrestrial solar radiation on a plane surface with the Whiteman and Allwine (1986) model, and included radiation attenuation through a cloudless atmosphere by using the sky transmissivity parametrization of Burridge and Gadd (1974).

The incoming short-wave radiative flux is composed of diffuse and direct radiation. The diffuse component being present during the whole daytime period is particularly evident in periods between the astronomical and local sunrises and sunsets. It originates from molecular (Rayleigh) scattering in the sky and from reflections of $K \downarrow$ on the surrounding terrain (Whiteman et al., 1989; Matzinger et al., 2003). The average daytime albedo, defined as $|K \uparrow / K \downarrow|$, is approximately 0.2 , which is in the expected range of values for a grassy surface (Brutsaert, 2005). The diurnal cycle of the daytime albedo (not shown) is characterized by smaller values around midday and higher values in the morning and the evening. This pattern is typical of homogeneous and uniform surfaces (Hoch and Whiteman, 2010). 
(a)

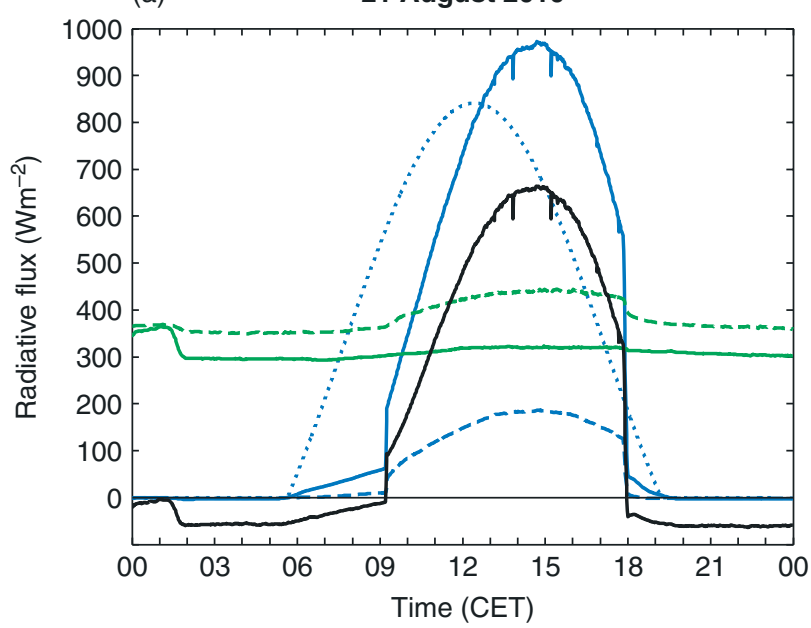

(c)

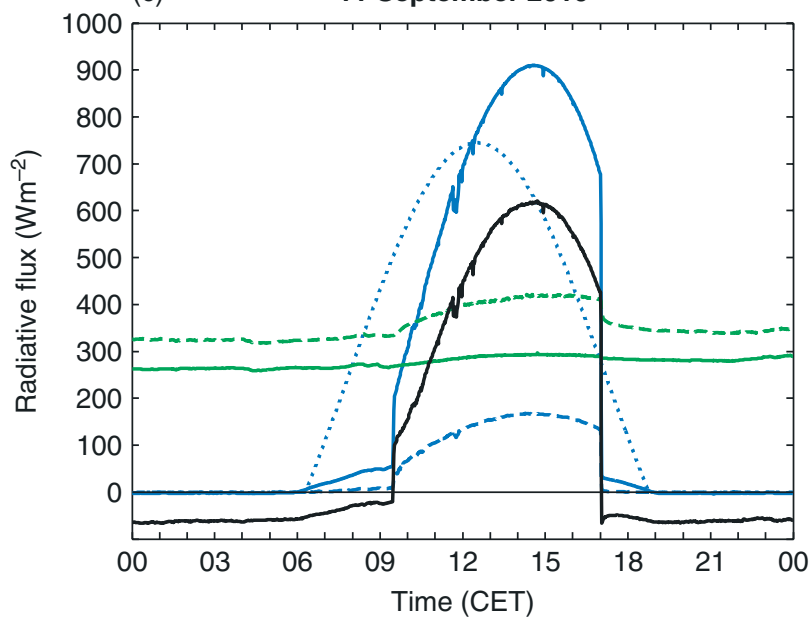

$L \downarrow$ $|L \uparrow|$ Theoretical $K \downarrow$ flat surface

(b)

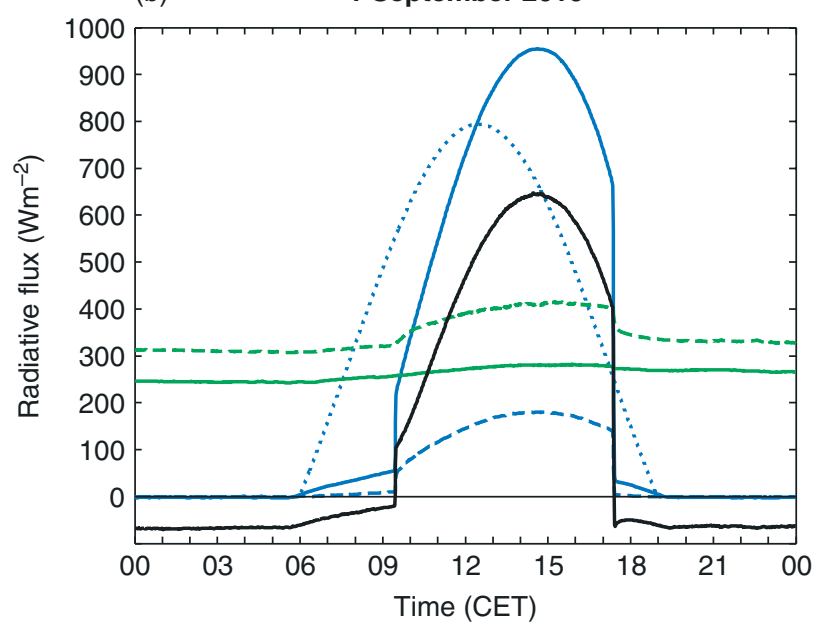

(d)

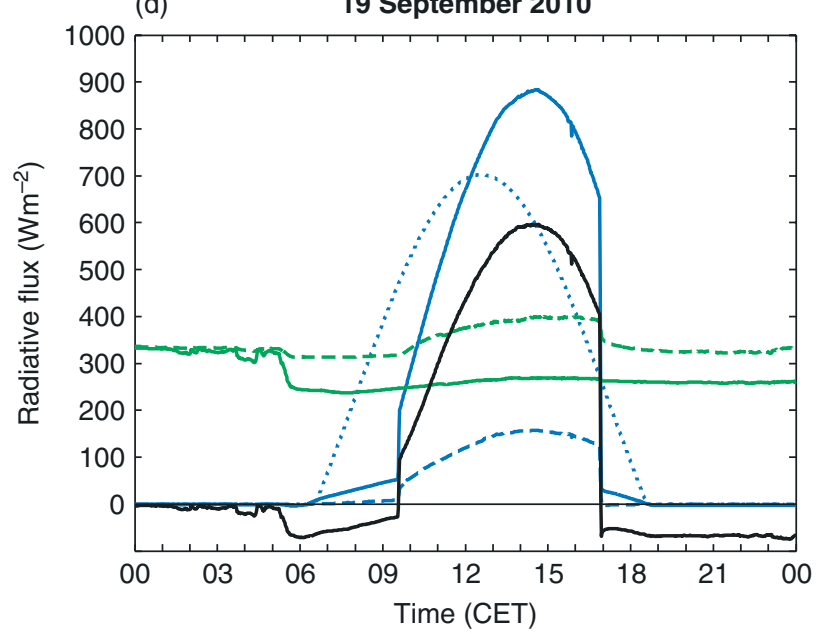

Figure 4. Slope-parallel radiation budget components measured at site T1 (slope: $30^{\circ}$ ) on four convective days. The absolute values of $K \uparrow$ and $L \uparrow$ are plotted. The $1 \mathrm{~min}$ sampling interval accurately captures the rapidly changing radiation budget around the transition periods.

The presence of a very smooth signal for $K \downarrow$ is indicative of clear-sky conditions. The maximum $K \downarrow$ is on average $20 \%$ greater than the theoretical maximum for flat terrain and occurs approximately $2 \mathrm{~h}$ later. These two characteristics are obviously site-specific, but they demonstrate how the slope and aspect of a site can significantly influence the local radiation budget. Overall, the downwelling long-wave radiation is relatively constant apart from a slight daytime increase due to higher air temperatures and two cases where nighttime clouds were present (21 August and 19 September), resulting in a larger $L \downarrow$. At night, $L \uparrow$ is relatively constant, and during the day it follows $K \uparrow$ owing to its coupling to the surface temperature.

In all cases, the reduction in $K \downarrow$ around the local sunset is large and rapid. On 11 September, the incoming shortwave radiation drops by $642 \mathrm{~W} \mathrm{~m}^{-2}$ in $3 \mathrm{~min}$, which is approximately the time it takes for the sun disk to disappear below the horizon. In subsequent sections, we will see how this sudden decrease in the radiative flux has profound implications on the atmospheric flow, and on the transition toward the night-time regime.

\subsection{Near-surface response around local sunset}

The geometric configuration of the experimental site leads to an evening 'shading front', which propagates from the bottom to the top of the slope. A series of photographs taken on a sample convective day (1 September 2010) are shown in Figure 5. The speed at which the shading front moves upslope changes throughout the season, since it depends on the angle between incident sunlight and the local relief shading the slope. The speed of the shading front could be quantified by using a solar radiation model and digital elevation data (e.g. Dozier and Frew, 1990).

Figure 6 shows the response of the surface temperatures measured along the slope at stations A1 to A5 on that same day, which is well representative of the other convective days studied. The surface temperature $T_{\mathrm{s}}$ is highly correlated with the incoming short-wave radiation and the local properties of the surface (aspect, inclination, surface type and moisture). The latter factors, along with instrumental errors, explain the differences between the five curves.

The impact of the shading front on the surface temperatures is substantial and in some cases, $T_{\mathrm{s}}$ drops by $10^{\circ} \mathrm{C}$ in less than $10 \mathrm{~min}$. The nonlinear decrease of $T_{\mathrm{s}}$ 

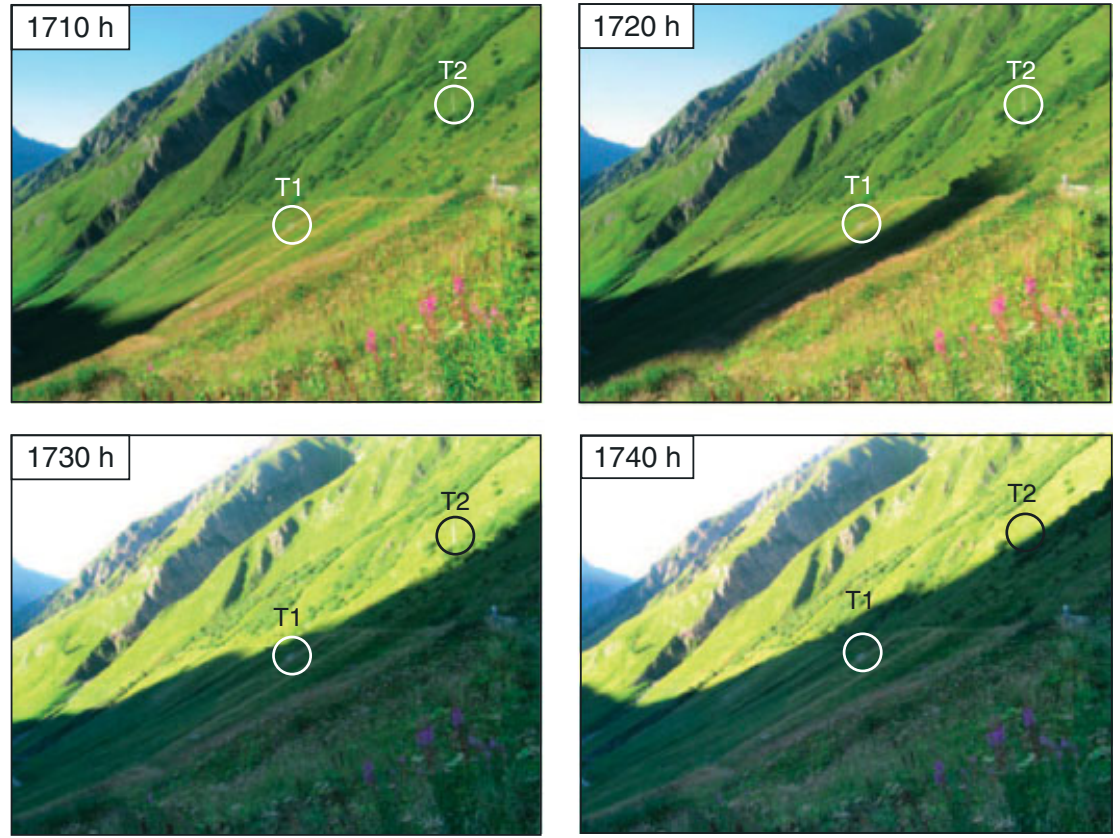

Figure 5. Photographs at $10 \mathrm{~min}$ intervals of the shading front propagating upslope across the measurement stations T1 and T2 on 1 September 2010. The small difference between 1730 and 1740 CET is due to the relief of the surrounding mountains.

seems to take place over two time-scales, one very short $(\mathcal{O}(\min ))$ and a longer one $(\mathcal{O}(\mathrm{h}))$. If we fit a sum of two exponentially decaying functions to $T_{s}$, these two timescales are approximately 5 and $180 \mathrm{~min}$. The short time-scale originates from the very abrupt decrease of the direct $K \downarrow$ resulting in a quasi-instantaneous drop in $T_{s}$. The longer time-scale is a superposition of gradually decreasing diffusive $K \downarrow$ and heat lost to the atmosphere through emitted longwave radiation and near-surface conduction.

Figure 7 shows median values of air and skin temperature as well as wind speed and direction around the local sunset at station $\mathrm{T} 1$ from the selected nine convective days. The near-surface temperature gradient is reversed 5 min after the local sunset. In contrast to $T_{s}$, which decreases by $\approx 7^{\circ} \mathrm{C}$ in $30 \mathrm{~min}$, the air temperature reduction is only slightly accelerated after the local sunset.

The near-surface up-valley winds stop a few minutes after the local sunset at station T1 (Figure 7(b)). Before the onset of downslope flow, a $15 \mathrm{~min}$ period with variable wind directions and very weak winds $\left(<0.5 \mathrm{~m} \mathrm{~s}^{-1}\right)$ is observed. Mahrt et al. (2010) refer to this as the 'early evening calm' period and it has been observed in a few other studies (Acevedo and Fitzjarrald, 2001; Mahrt et al., 2001). About $1.5 \mathrm{~h}$ after the local sunset, the downslope flow velocities begin to stabilize around $1.5 \mathrm{~m} \mathrm{~s}^{-1}$ with small fluctuations.

\subsection{Evolution of the atmospheric vertical structure}

Atmospheric profiles of potential temperature, wind speed and wind direction from the tethered balloon soundings for three of the nine convective days are shown in Figure 8. For each profile, a moving average over $3 \mathrm{~m}$ was used to smooth out small-scale fluctuations associated with instrumental errors. The lowest data point of the profile was usually taken at approximately $1 \mathrm{~m}$ above the surface. In this section, heights are not reported normal to the surface, but vertically above the ground. Although a range of behaviours

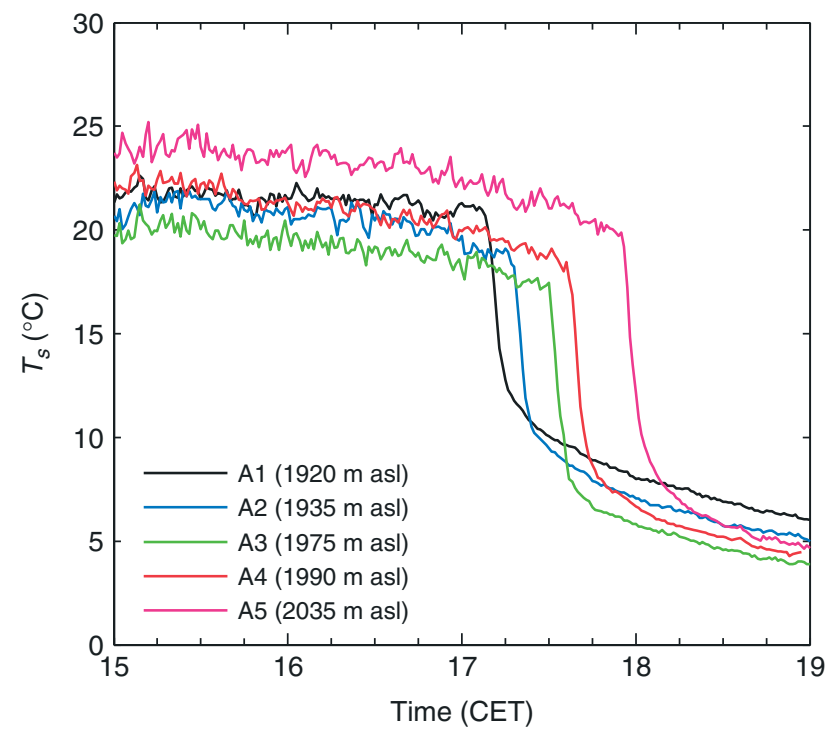

Figure 6. Abrupt decrease in surface temperature on 1 September 2010 in response to the shading front propagating upslope, at stations A1 to A5.

is observed in the atmospheric profiles, we find several repeated patterns.

The daytime soundings are characterized by an homogeneous layer of upvalley flow (Figure 8(c)). In a few cases (e.g. 21 August at $1747 \mathrm{~h}$ ), the near-surface winds are oriented upslope prior to the local sunset. A similar directional wind shear was also reported by Rotach et al. (2008), where the authors mention that the influence of anabatic flow is confined to a depth of a few tens of metres above the ground. On 11 September at $1641 \mathrm{~h}$ (Figure 8(b)), an upvalley jet is found between 150 and $200 \mathrm{~m}$ above the surface.

The nocturnal structure of the atmosphere is more complex and is organized into several layers as a result of stable stratification (Figure 8(a)). Following the local sunset, the daytime upvalley flow layer transitions from the bottom as the atmosphere adjusts to the rapid changes 

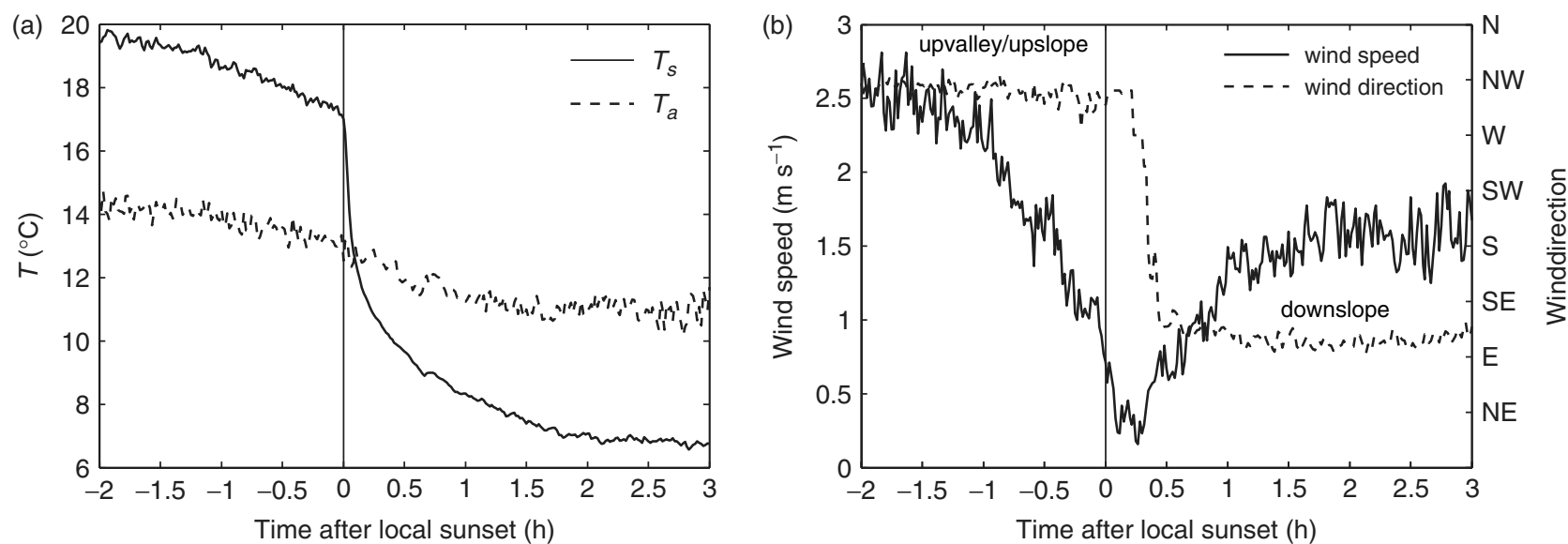

Figure 7. Medians of (a) air and surface temperature, (b) wind speed and direction around the evening transition measured at station T1 for the nine convective days. The air temperature was measured with a sonic anemometer installed $2.5 \mathrm{~m}$ above the surface. The wind speed and direction were measured at 2.7 and $2.3 \mathrm{~m}$ above ground with a cup anemometer and a wind vane, respectively.

in the radiation budget. Close to the surface, a shallow layer of 'skin flow' has been shown to form under certain conditions (Figure 8(b)). This very shallow katabatic flow forms locally (Manins, 1992; Mahrt et al., 2001) and rarely exceeds a few metres in depth. With the presence of this shallow drainage flow, $\partial \bar{u} / \partial z_{\text {vert }}<0$ in most of the nearsurface region at night, where $z_{\mathrm{vert}}$ is in the direction parallel to the gravitational vector. Above the skin flow ( $\gtrsim 30 \mathrm{~m}$ ), a layer of downvalley flow presumably originating from the side valley (westerly winds) is occasionally observed (e.g. on 1 September) but most of the time a downvalley flow is oriented along the main valley axis (southerly winds). However the downvalley circulation is not as persistent as the daytime upvalley flow, and its strength varies through the early night. Note that the local curvature in the alongvalley topography could also induce complex secondary circulations, as discussed in Weigel and Rotach (2004). These circulations would result in additional advective fluxes; however their quantification was not possible and is beyond the scope of this article.

Wind velocities prior to local sunset are usually on the order of 1 to $3 \mathrm{~m} \mathrm{~s}^{-1}$, while nocturnal wind velocities are generally weaker $\left(0-2 \mathrm{~m} \mathrm{~s}^{-1}\right)$. This was also observed by Weigel and Rotach (2004), who found that on all 'valleywind days' of the MAP-Riviera campaign, the night-time downvalley flow was significantly weaker than the equivalent daytime upvalley circulation, with wind velocities rarely greater than $1 \mathrm{~m} \mathrm{~s}^{-1}$.

The near-surface region with large temperature gradients is very shallow, typically between 5 to $10 \mathrm{~m}$ thick, and these gradients can be relatively large (Figure 8(a)). For instance, the strength of the nocturnal potential temperature inversion reaches $0.58 \mathrm{~K} \mathrm{~m}_{\text {vert }}^{-1}$ at $1927 \mathrm{~h}$ on 11 September.

Interestingly, on 1 September, a sounding was taken exactly at the local sunset $(1730 \mathrm{~h})$. The associated potential temperature profile displays a $50 \mathrm{~m}$ neutrally buoyant layer above the surface with perfectly calm winds. This suggests that the 'early-evening calm' period is felt through a significant portion of the lower atmosphere.

\subsection{Evolution of slope flows}

On 21 August, the shading front took $45 \mathrm{~min}$ to travel from station S1 to T2 (Figure 9), while on 11 September it took only $25 \mathrm{~min}$. Due to the seasonal variations in the propagation of the shading front, instead of medians we present three sample days of wind vectors around the evening transition each separated by a 10-day period (Figure 9). A geometric correction was applied to wind velocities collected by the horizontally mounted cup anemometer at station S1. No corrections were used at station S2 since it is located on a flat terrace and the sensor is assumed to be aligned with the flow streamlines.

The 'transition front', marked by the flow reversal from upvalley/upslope to downslope, moves upwards on the slope. During the early evening calm period, the cup anemometers (stations S1 and S2) are unable to detect the very light winds. Based on stations T1 and T2, the quiescent period lasts between 10 to $30 \mathrm{~min}$. On 11 September, the downvalley flow component is occasionally more important, particularly closer to the valley floor. At higher altitudes, the flow appears more independent from what is observed below. On that same day, station S2 seems to be affected by largerscale circulation patterns, from which lower stations appear sheltered. Indeed, at these locations, the wind vectors reveal that the katabatic flow forms locally on the slope between altitudes of 1900 and $2200 \mathrm{~m}$.

Overall, Figure 9 shows that the 'transition front' propagates upslope on a steep west-facing slope of a narrow Alpine valley as a result of topographic shading. This is contrary to the model developed by Hunt et al. (2003) for gentle and unobstructed slopes in wide valleys.

The structure of the near-surface velocity and potential temperature fields during the transition period is presented in Figure 10. The winds turn upslope in the last hour before the local sunset. The flow does not vary with height prior to the local sunset, apart from a slight directional shear. Following the transition, the wind velocities become very weak, particularly close to the surface. The rapid surface cooling (Figure 6) leads to a growing stably stratified layer and $10 \mathrm{~min}$ after the drop in $R_{\mathrm{n}}$ we see the first sign of a downslope flow at $1.5 \mathrm{~m}$ above the surface. The katabatic layer grows and $20 \mathrm{~min}$ after the local sunset it reaches the highest level on the sensor tower $(\approx 5 \mathrm{~m})$. About an hour after the local sunset, the surface winds are of $1.2 \mathrm{~m} \mathrm{~s}^{-1}$. Due to poor mixing caused by the stable stratification, the velocity gradients are substantial $\left(\approx-0.2 \mathrm{~s}^{-1}\right)$. 
(a) Potential temperature
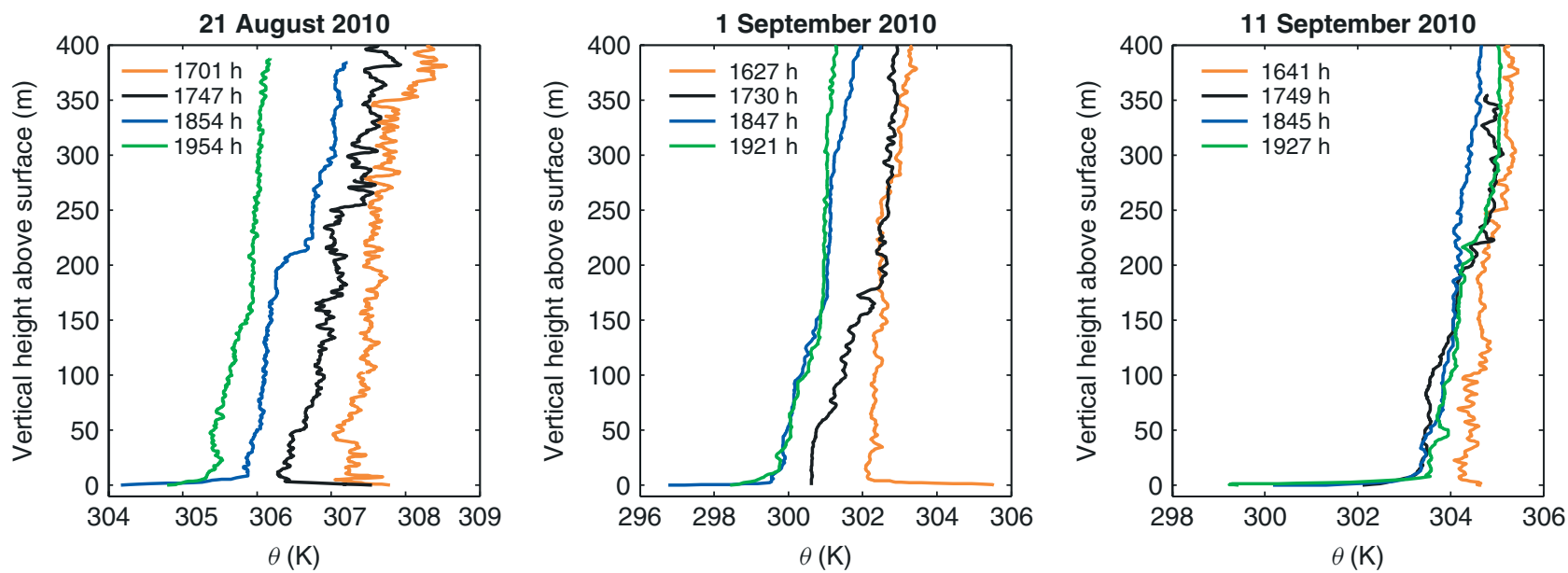

(b) Wind speed
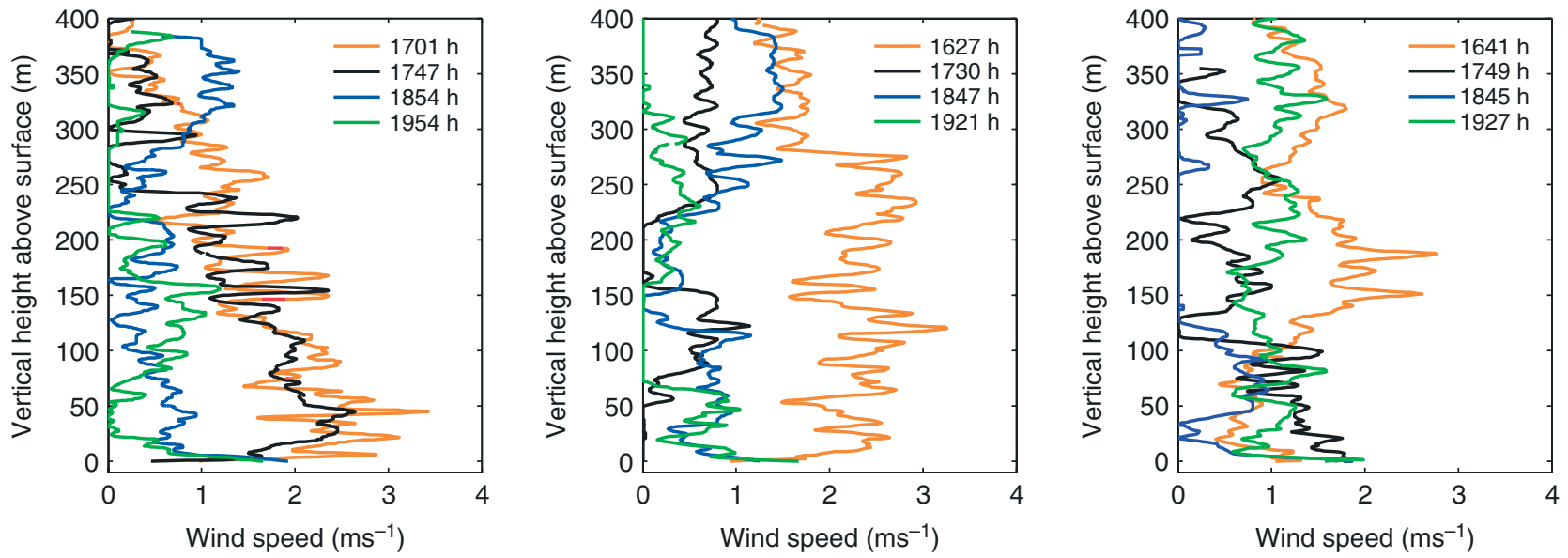

(c) Wind direction
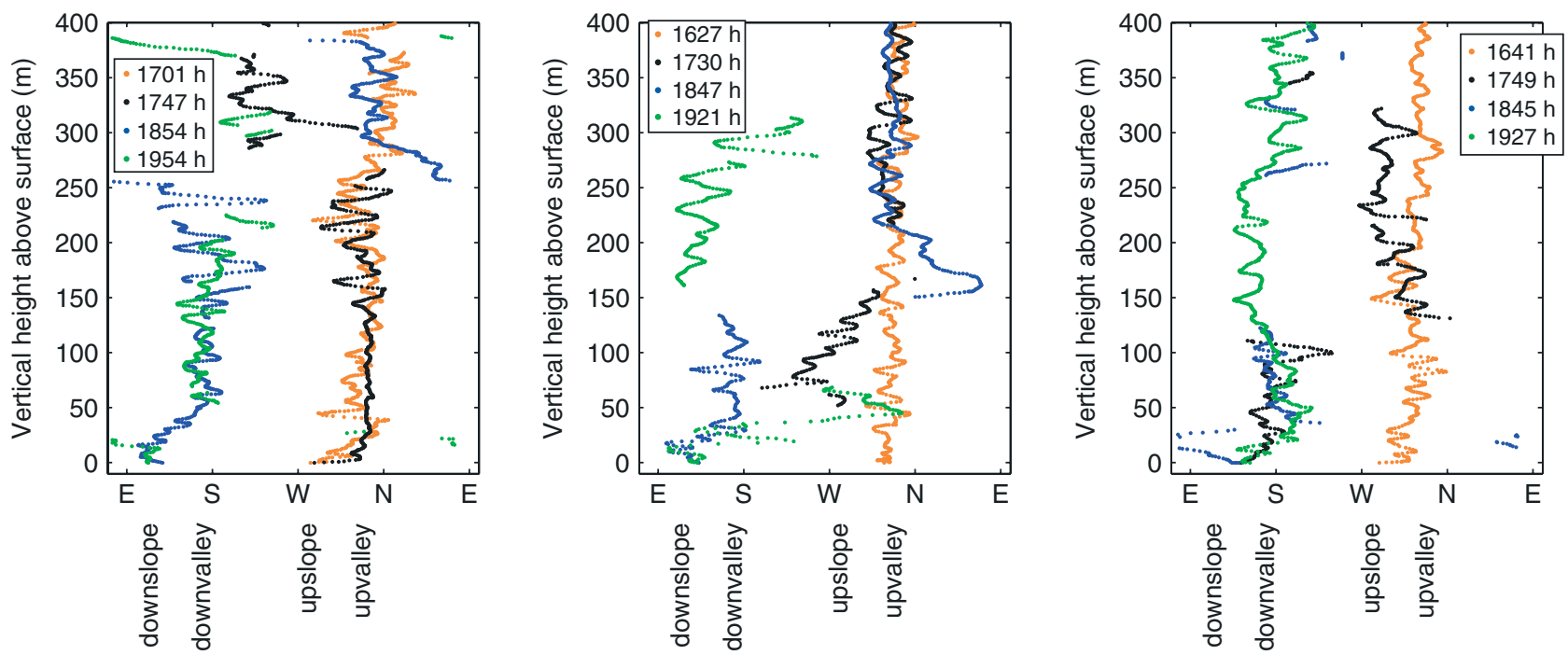

Figure 8. Profiles of (a) air potential temperature, (b) wind speed and (c) wind direction obtained with the tethered balloon system for three convective days around the local sunset. The local sunsets at the launching site (elevation $1950 \mathrm{~m}$ asl) are approximately at $1800 \mathrm{~h}$ on $21 \mathrm{August}, 1730 \mathrm{~h}$ on 1 September and $1705 \mathrm{~h}$ on 11 September 2010. The heights reported are vertical distances (not normal to the slope). All times reported are Central European Time (CET), and correspond to the halfway point of the sounding.

The velocity and temperature structure of the developing of the wind speed maximum. It is useful to compare the katabatic layer is shown in Figure 11 for a few sample main characteristics of the katabatic layer with the classical convective days. The presence of a skin flow is obvious, scaling estimates found in the literature. Based on a hydraulic although measurements between 0 and $1 \mathrm{~m}$ above the model, Manins and Sawford (1979) derived the following surface would be needed to determine the exact location expressions for the depth of the katabatic layer $H$, the 
(a) 21 August 2010
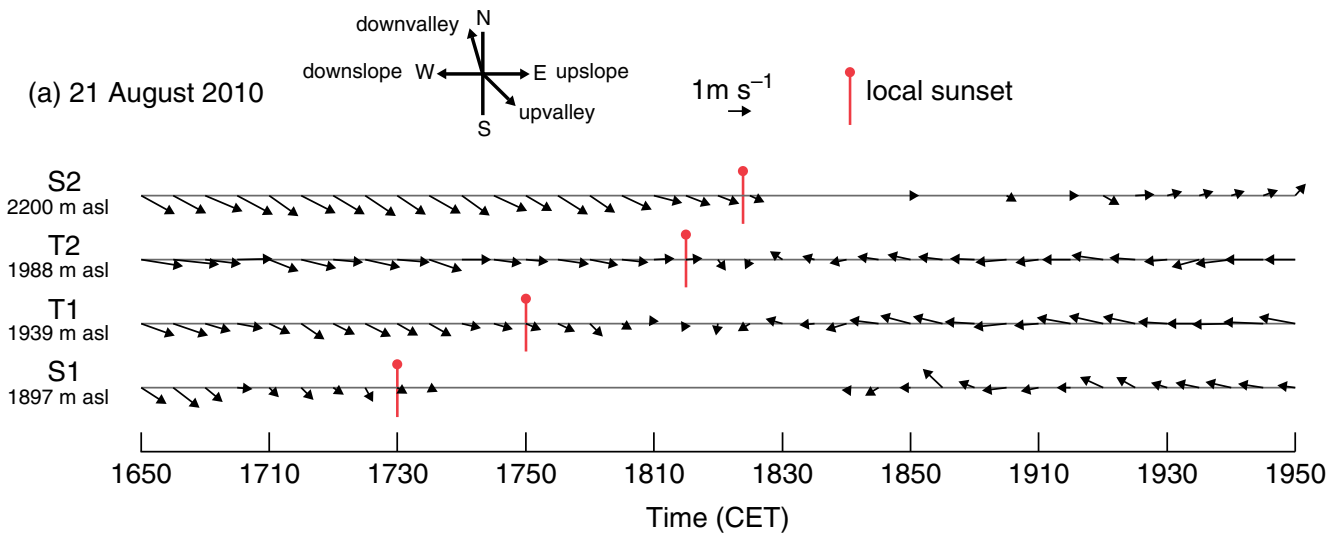

(b) 1 September 2010

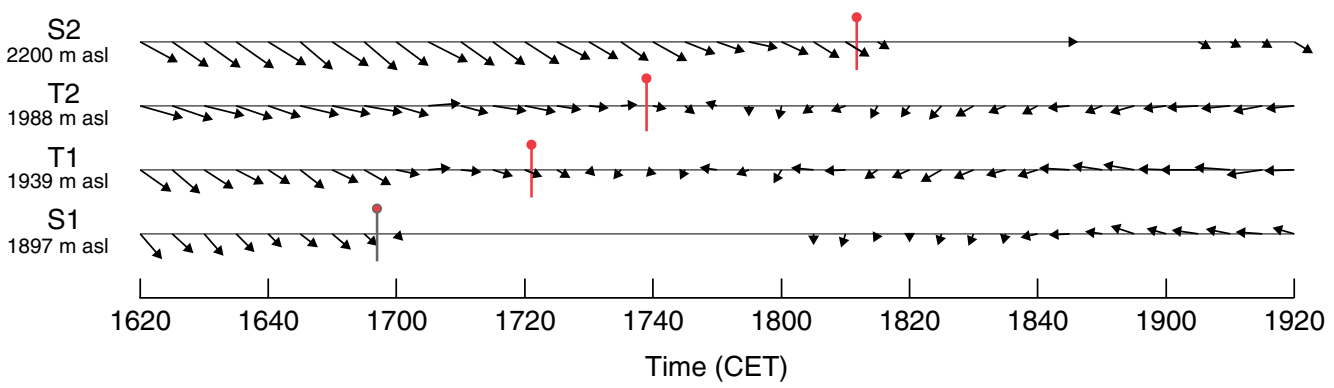

(c) 11 September 2010

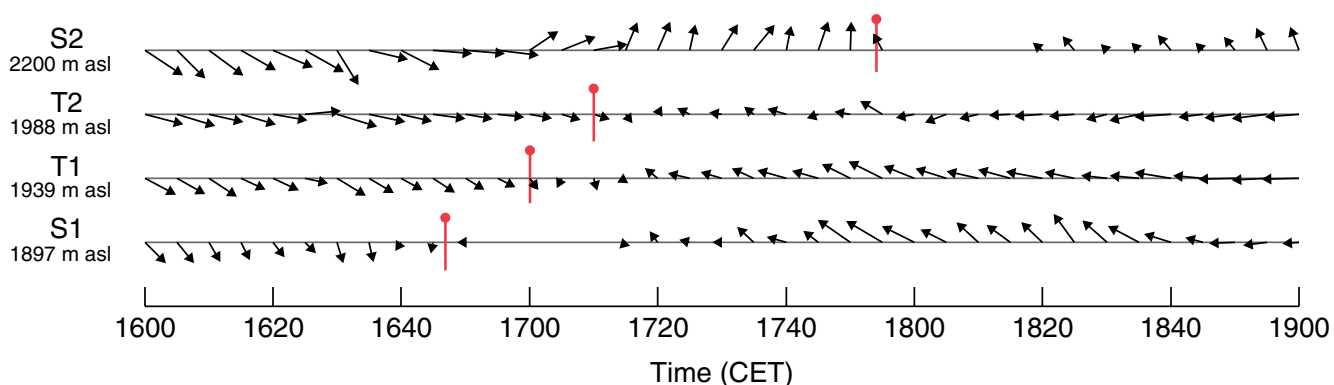

Figure 9. Five-minute averaged wind vectors along the slope around the local sunset on (a) 21 August, (b) 1 September and (c) 11 September 2010. The local sunset is indicated by a red line with a circle. $\mathrm{A}_{1} \mathrm{~m} \mathrm{~s}^{-1}$ reference vector is shown at the top of the figure.

katabatic flow velocity $U$ and the buoyancy parameter $g^{\prime}$ (Nappo and Rao, 1987, provide a clear summary):

$$
\begin{aligned}
H & =C_{1}(\sin \alpha)^{2 / 3} s, \\
U & =C_{2}(\sin \alpha)^{2 / 9}\left(\frac{g}{\theta_{\mathrm{va}}} \overline{w^{\prime} \theta^{\prime}{ }_{0}} s\right)^{1 / 3}, \\
g^{\prime} & =C_{3}(\sin \alpha)^{-8 / 9}\left(\frac{g}{\theta_{\mathrm{va}}} \overline{w^{\prime} \theta^{\prime}{ }_{0}}\right)^{2 / 3} s^{-1 / 3},
\end{aligned}
$$

where $C_{1}, C_{2}$ and $C_{3}$ are constants, $\alpha$ is the slope angle, $s$ is the slope distance from the crest, and $\overline{w^{\prime} \theta^{\prime}}$ is a slopeaveraged kinematic heat flux. Note that $g^{\prime}=g \sin \alpha \bar{d} / \overline{\theta_{\mathrm{va}}}$, where $\bar{d}=\overline{\theta_{\mathrm{v}}}-\overline{\theta_{\mathrm{va}}}$ is the temperature deficit, defined as the difference between the virtual potential temperature of air $\overline{\theta_{\mathrm{v}}}$ and the unperturbed virtual potential temperature field $\overline{\theta_{\mathrm{va}}}$. The bar is used for time averaging and the primes indicate a deviation from the temporal mean.

We evaluate (2) to (4) at site T2, at a height of $1.5 \mathrm{~m}$ normal to the surface. Following Briggs (1981), we take $C_{1}=0.037$, $C_{2}=2.15$ and $C_{3}=12.6$. Here we assume that the relevant length-scale is the along-slope distance between station T2 and $2400 \mathrm{~m}$ asl, where there is a sharp discontinuity in the slope angle (Figure 2). Above this point, we suspect that the downslope flow upstream is diverted away in two adjacent gullies. For that segment between $z=1988$ and $2400 \mathrm{~m}$ asl, $\alpha \approx 40^{\circ}$, and $s=550 \mathrm{~m}$. In the early night-time period, typically $\overline{\theta_{0}} \approx 285 \mathrm{~K}$ and $\overline{w^{\prime} \theta^{\prime}}=-0.02 \mathrm{~m} \mathrm{~K} \mathrm{~s}^{-1}$. Using these values, we obtain $H=15 \mathrm{~m}, U=1.4 \mathrm{~m} \mathrm{~s}^{-1}$. These two estimates are in excellent agreement with the observations in Figure 11, even if the katabatic velocity profile deviates from the classical shape due to the presence of a skin flow. For the buoyancy parameter, we obtain $g^{\prime}=0.018 \mathrm{~m} \mathrm{~s}^{-2}$, thus $\bar{d}=0.5 \mathrm{~K}$. From Figure $11, \bar{d} \approx 1-4 \mathrm{~K}$. The discrepancy between the estimate and the observed value of $\bar{d}$ could be due to neglected cooling processes in the hydraulic model of Manins and Sawford (1979) such as radiative flux divergence. Note that the Brunt-Väisälä frequency $N=\sqrt{(g / \bar{\theta}) \cdot(\partial \bar{\theta} / \partial z)}$ was typically found to increase linearly from $5 \mathrm{~min}$ to $1.5 \mathrm{~h}$ after the local sunset, until it reached a nearly constant value of $\approx 0.065 \mathrm{~Hz}$.

Figure 12 summarizes the sequence of events taking place around the early evening transition period on the slope. 


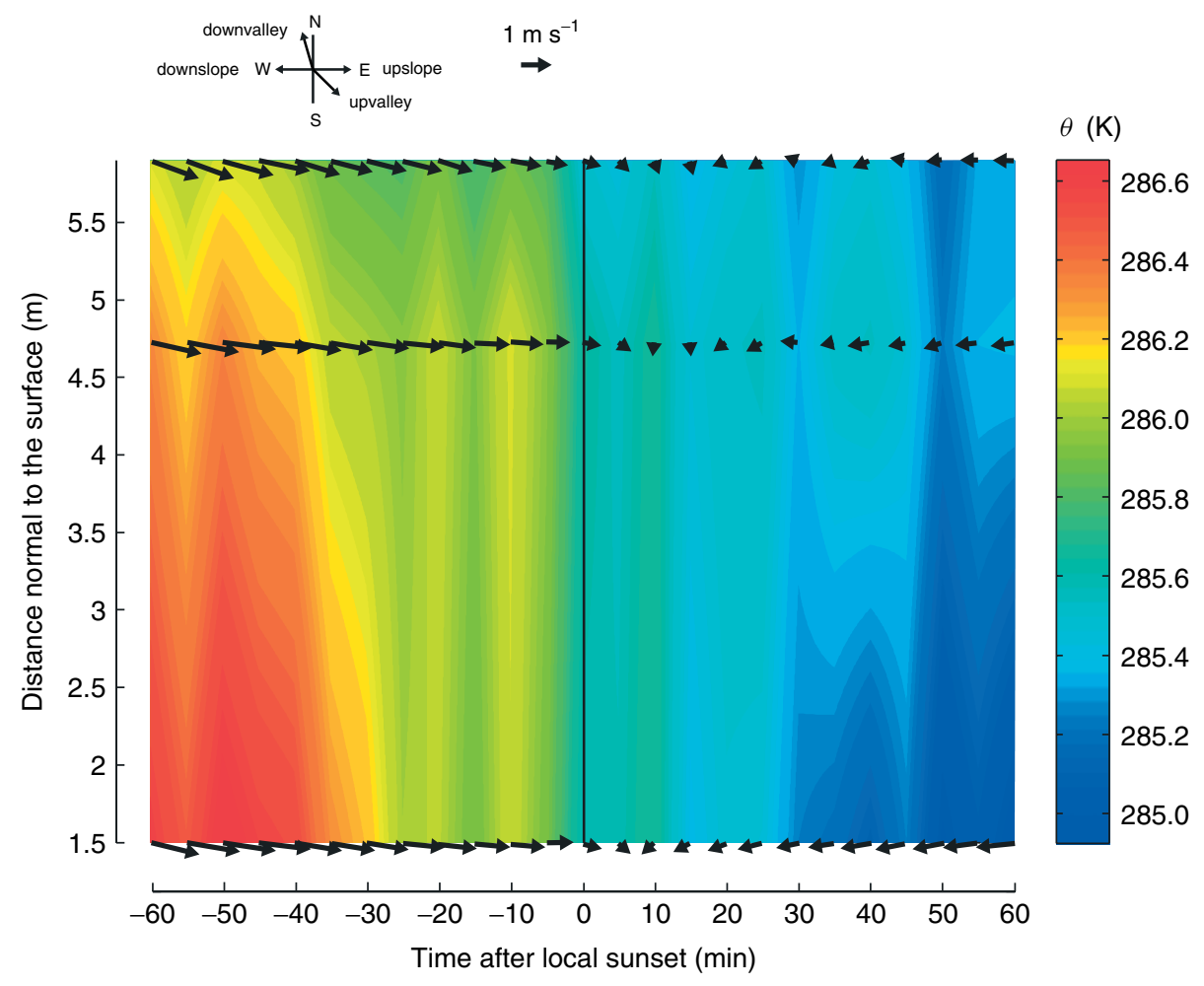

Figure 10. Profiles of 5 min averaged wind vectors at station T2 using the median of the nine convective days around the local sunset, with interpolated potential temperatures (colour shading). The measurements heights are 1.5, 4.7 and $5.9 \mathrm{~m}$ above the surface.

(a)

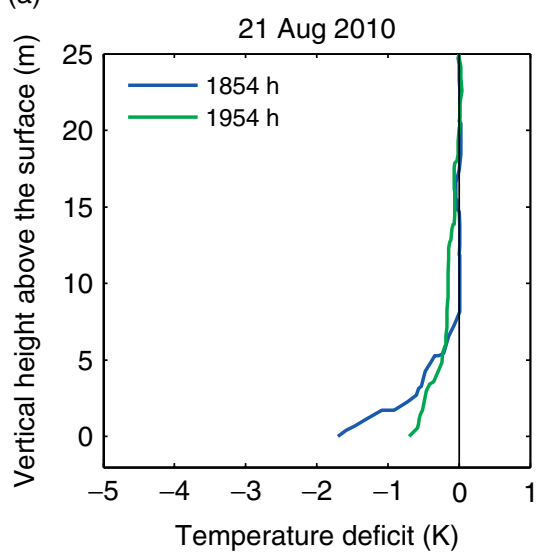

(b)

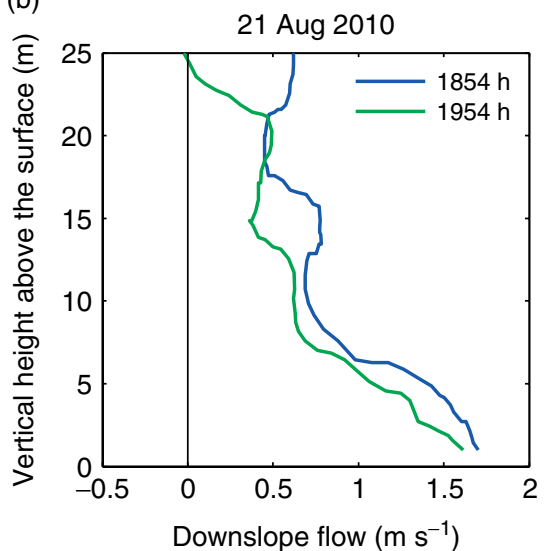

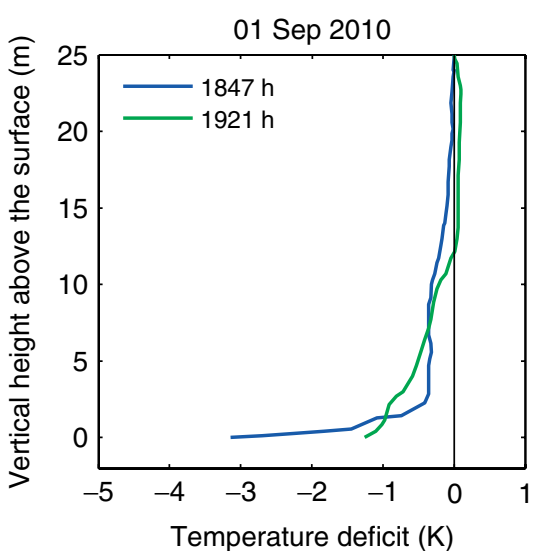

Temperature deficit $(\mathrm{K})$

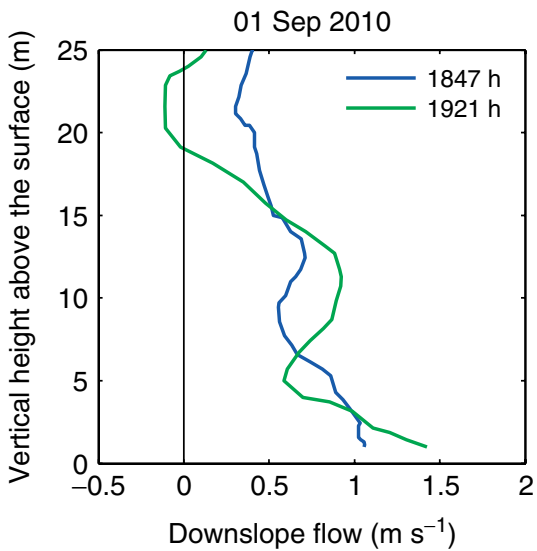

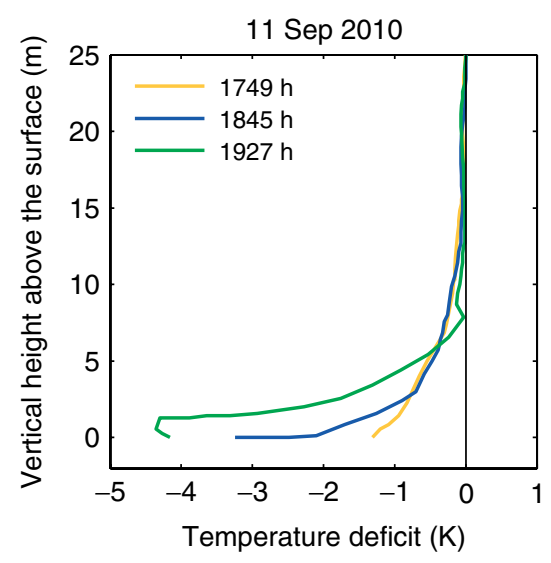

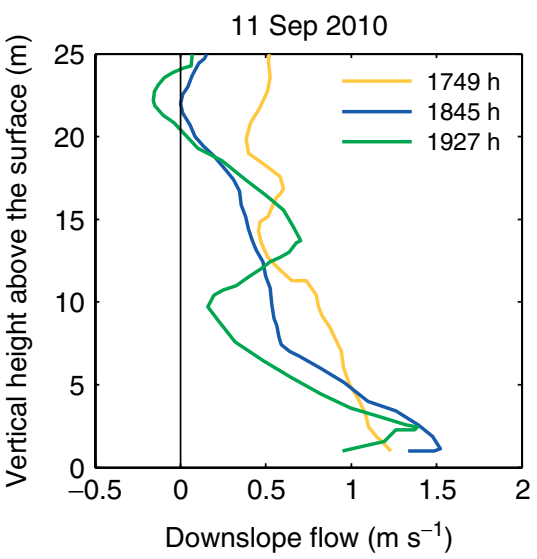

Figure 11. Atmospheric profiles of (a) temperature deficit $d$ and (b) downslope flow velocities in the katabatic layer. The temperature deficit $d$ is the difference between $\theta_{\mathrm{v}}$ and the unperturbed potential temperature $\theta_{\mathrm{va}}$, which we assume to be equal to the temperature at $25 \mathrm{~m}$ above the surface. The data were obtained with the tethered balloon system during the early night-time period of the three convective days presented in Figure 8. 

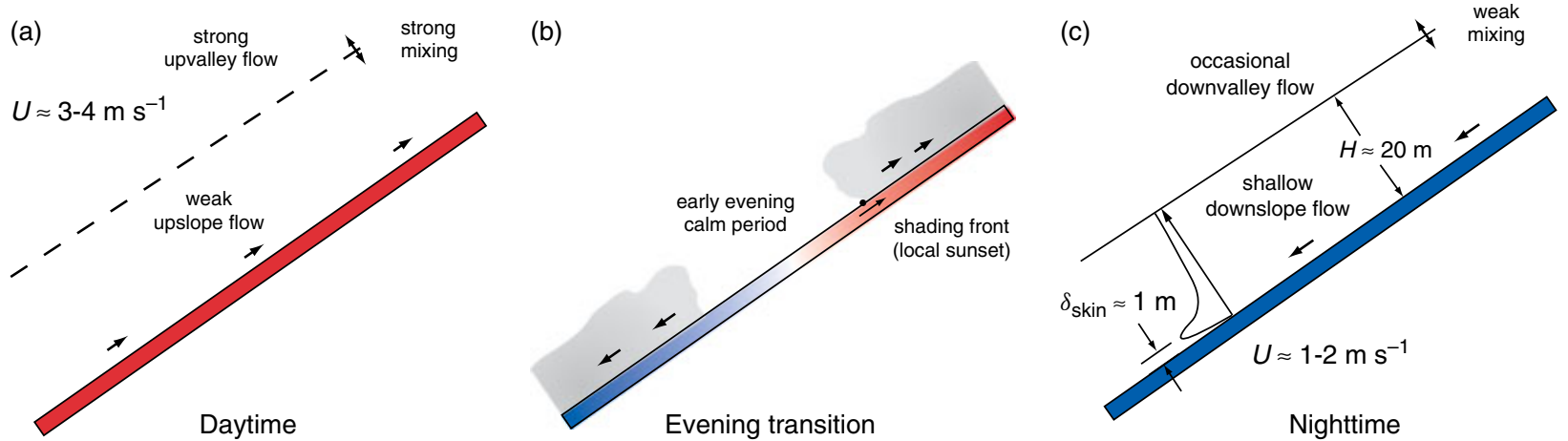

Figure 12. Sequence of events around the evening transition on the slope, with (a) daytime conditions, (b) conditions around the local sunset and (c) early night-time conditions. The along-slope surface temperature distribution is also qualitatively illustrated (blue: cold, red: warm). The exact border shapes on each side of the early evening calm period are unknown.

During the day (Figure 12(a)), there is a strong mixing between the layers of weak upslope flow and strong upvalley flow. Close to the surface, the winds are oriented upvalley for most of the day and, in some cases prior to the local sunset, the winds become oriented upslope. The local sunset completely changes the dynamics of the slope flow system. Following the shading front which is propagating upslope, the skin temperatures drop substantially (by $\approx 7^{\circ} \mathrm{C}$ in $30 \mathrm{~min}$ ) and the winds become very light, marking the start of the early evening calm period (Figure 12(b)). Given the surface divergence of airflow associated with the transition front, we expect weak subsidence, however we were unable to successfully detect it in the measurements. In response to the radiative cooling of the surface, a stable boundary layer forms and a shallow layer of downslope winds grows from the surface. The early periods of the night are well described by classical scaling of katabatic flows by Manins and Sawford (1979) (Figure 12(c)). The stable stratification significantly limits the vertical mixing and distinct layers of flow are found. Above the katabatic flow layer, occasional downvalley flow is observed.

\subsection{Momentum and heat budget analysis}

In this section, we are interested in understanding the mechanisms responsible for the destruction of daytime winds and the onset of the drainage flow right after the local sunset. Following Manins and Sawford (1979), for a two-dimensional flow and neglecting Coriolis forces, the momentum balance in a terrain-following coordinate system is given by

$$
\begin{array}{rrr}
\frac{\partial \bar{u}}{\partial t}=-\bar{u} \frac{\partial \bar{u}}{\partial x}-\bar{w} \frac{\partial \bar{u}}{\partial z}- & \frac{g \bar{d} \sin \alpha}{\overline{\theta_{\mathrm{va}}}} \\
\text { I II III } & \text { IV } \\
& -\frac{\partial \overline{u^{\prime} w^{\prime}}}{\partial z}-\frac{1}{\bar{\rho}} \frac{\partial\left(\bar{p}-\overline{p_{\mathrm{a}}}\right)}{\partial x}, \\
\mathrm{~V} & \mathrm{VI}
\end{array}
$$

with $(x, z)$ respectively parallel (aligned with the mean wind) and normal to the slope, and where $u$ is the streamwise wind velocity, $w$ is the wind velocity normal to the surface, $t$ is time, $\rho$ is the air density, $p$ is the local pressure, and $p_{a}$ is the ambient pressure field. In (5), term I is the storage of momentum, term II is the horizontal advection of momentum, term III is the advection of momentum normal to the surface, term IV is the buoyancy acceleration, term $\mathrm{V}$ is the turbulent momentum flux divergence and term VI is the along-slope pressure gradient.

For the same coordinate system, neglecting molecular conduction of heat and latent heat releases, the thermal energy equation can be expressed as

$$
\begin{gathered}
\frac{\partial \overline{\theta_{\mathrm{v}}}}{\partial t}=-\bar{u} \frac{\partial \overline{\theta_{\mathrm{v}}}}{\partial x}-\bar{w} \frac{\partial \overline{\theta_{\mathrm{v}}}}{\partial z}-\frac{\partial \overline{w^{\prime} \theta_{\mathrm{v}}^{\prime}}}{\partial z}-\frac{1}{\bar{\rho} c_{p}} \frac{\partial \overline{R_{\mathrm{n}}}}{\partial z}, \\
\text { I }
\end{gathered}
$$

where $c_{p}$ is the specific heat capacity of air. In (6), term I describes the storage of heat, term II is the horizontal advection of heat, term III represents the advection of heat normal to the surface, term IV is the sensible heat flux divergence and term $\mathrm{V}$ describes the radiation divergence.

In the past, (5) and (6) have been integrated over the depth of the slope-flow layer (e.g. Manins and Sawford, 1979; Papadopoulos and Helmis, 1999). Since our experimental measurements do not fully cover the depth of the slope-flow layer, we choose to evaluate (5) and (6) at a point to better understand the importance of the different mechanisms governing the transfer of heat and momentum.

This analysis focuses on measurements taken at sonic anemometer 'A' at station T2 (1.5 m above the surface) in the slope-flow layer around the local sunset (Figure 13). All terms in the momentum and thermal energy equations are directly obtained using our measurements, except for terms VI in (5) and V in (6) which have to be taken as residuals. For the calculation of terms involving the derivative along the slope, we use data from station $\mathrm{T} 1$ when it is approximately aligned with the flow streamlines. This allows us to evaluate term II in (5) and (6) only when the winds are flowing downslope though, which is $25 \mathrm{~min}$ after the local sunset. The derivatives along $z$ were evaluated with sonic anemometers 'A' and ' $E$ ', respectively at 1.5 and $4.7 \mathrm{~m}$ above the surface. All derivatives are evaluated with forward finite differences, and $5 \mathrm{~min}$ averages are used.

In Figure 13(a), all budget terms are small during the earlyevening transition period. During the day, the friction term (V) is partly balanced by the buoyancy acceleration (term IV). At night, as expected, the buoyancy term (IV) drives the katabatic flow, along with advection of momentum normal to the surface (term III). Indeed, large gradients of along-slope wind velocities are observed (Figure 10), in combination with weak positive velocities normal to 
(a)

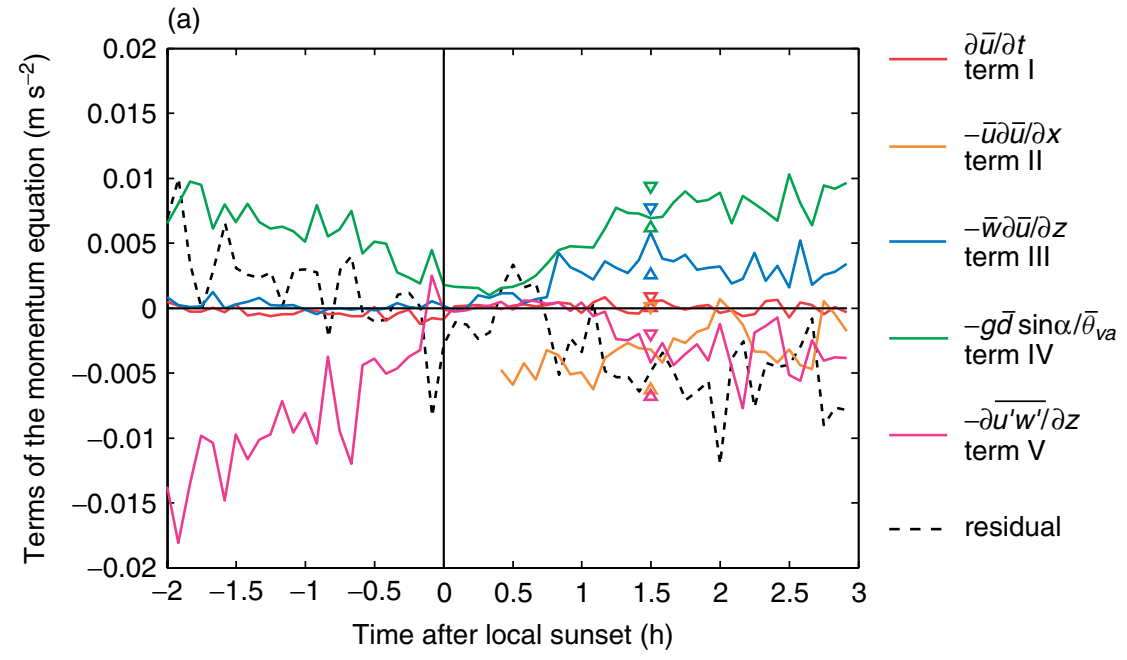

(b)

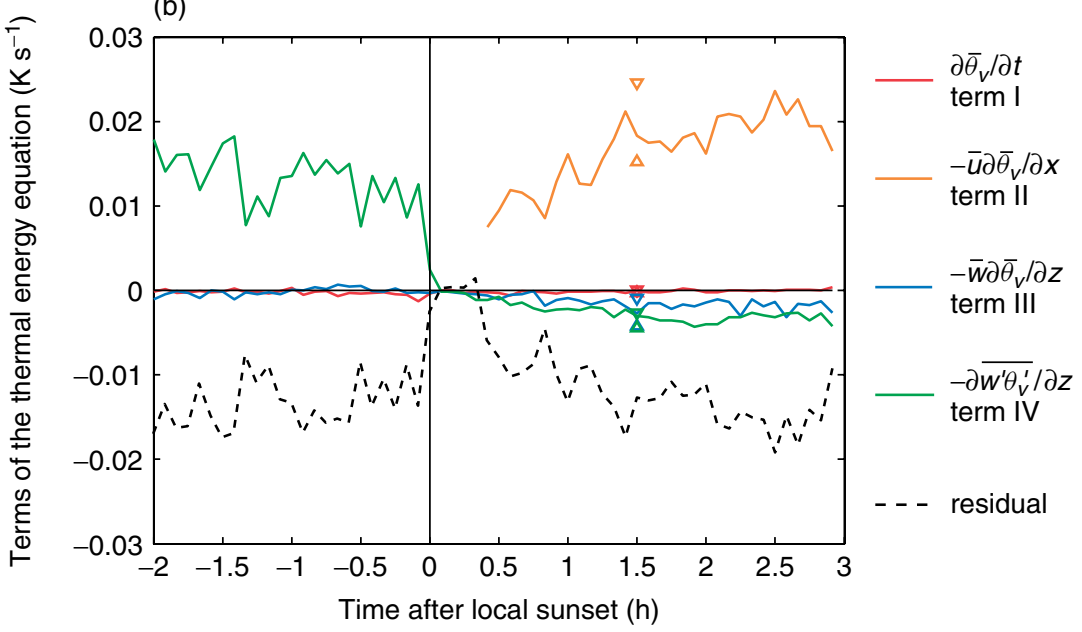

Figure 13. Median values of the terms in (a) the momentum (5) and (b) the thermal energy (6) equations evaluated at the lowest sonic anemometer $(z=1.5 \mathrm{~m})$ from station T2 for the nine convective days. The along-slope advective terms are plotted only when the katabatic flow is fully initiated $(\approx 25 \mathrm{~min}$ after local sunset), given that the horizontal advective flux (term II) cannot be estimated otherwise. The up- and down-pointing triangles indicate the interquartile range for each of the terms $1.5 \mathrm{~h}$ after the local sunset.

the surface $\left(\bar{w} \approx 1.5 \mathrm{~cm} \mathrm{~s}^{-1}\right)$, which are suspected to be $X$ topographically induced. Both the friction term $(\mathrm{V})$ and $\mathrm{X}$ the horizontal advective flux of momentum (II) act to decelerate the flow in the early night. During the period of interest, significant fluctuations in the friction term $(\mathrm{V})$ are found, possibly due to the unsteady flow dynamics in the near-surface region. The balance seems to indicate a local decrease in velocity and a strong rise in pressure, which could be caused by an 'internal hydraulic adjustment' when the downslope flow interacts with the cold-air pool at the bottom of the valley (Fernando, 2010). More observations are needed to verify this hypothesis. The residual term (VI) is significant over the whole transition period, either due to errors in the calculation of the other terms or because the pressure gradient is actively involved in the flow dynamics.

From (5), we can infer a time-scale $\tau_{\mathrm{r}}$ for the slope flow reversal. Right after the local sunset, if we neglect friction effects (Hunt et al., 2003), we can assume that the flow reversal occurs when the inertia-driven upslope flow is suppressed by the buoyancy force due to near-surface air cooling, thus when $\bar{u} \partial \bar{u} / \partial x \approx g \bar{d} \sin \alpha / \bar{\theta}$. Unfortunately, we have no data to explicitly describe the inertial term right after the local sunset, so we assume it is on the order $U_{\text {up }}^{2} / X$, where $U_{\text {up }}$ is a typical upslope velocity prior to sunset and
$X$ is the distance from the bottom of the slope. Taking $X=300 \mathrm{~m}, U_{\mathrm{up}}=0.4 \mathrm{~m} \mathrm{~s}^{-1}$, and using measurements of the katabatic acceleration, we find $\tau_{\mathrm{r}} \approx 22 \mathrm{~min}$, which is in remarkable agreement with the actual duration of the early-evening calm period.

Figure 13(b) shows that, during daytime, the convergence of sensible heat flux warms up the air, and possibly radiative flux divergence acts to cool it down. During the transition period, the sensible heat flux divergence is relatively constant and rapidly decays very close to local sunset. It roughly takes $1.5 \mathrm{~h}$ after the local sunset for the terms to stabilize around a nearly constant value. At night, the heat supplied by warm-air advection (term II) greatly exceeds the cooling from advective fluxes normal to the surface (term III) and sensible heat flux divergence (term IV). This imbalance indicates that other terms (e.g. radiative flux divergence) play an important role in the heat balance and should be more carefully investigated in the future. After the local sunset, the storage term is again close to zero, with negative values on average $\left(\approx-0.3^{\circ} \mathrm{Ch}^{-1}\right)$.

Overall this analysis shows that advective terms are significant in the local momentum and heat equations, and that it takes approximately $1.5 \mathrm{~h}$ after the local sunset for the katabatic flow to reach a quasi-equilibrium state. Note that for the height-integrated equations, Papadopoulos 
et al. (1997) found that the balance for momentum was predominantly between the katabatic acceleration (term IV) and the surface friction (term V). For the integrated energy balance, they found a steady balance between the downslope advection (term II) and sensible heat flux (term IV).

\subsection{Evolution of turbulent kinetic energy}

The turbulent kinetic energy $k$ (TKE) is a crucial variable to monitor during the evening transition period (Nadeau et al., 2011), as it reflects the balance between production, destruction, transport and storage of atmospheric turbulence in the ABL. The TKE is defined as

$$
\bar{k}=\frac{1}{2}\left(\overline{u^{\prime 2}}+\overline{v^{\prime 2}}+\overline{w^{\prime 2}}\right),
$$

where $u$ and $v$ are the horizontal wind speeds and $w$ is the wind speed normal to the surface. The TKE budget equation written using summation notation is

$$
\begin{aligned}
& \frac{\partial \bar{k}}{\partial t}+\overline{u_{j}} \frac{\partial \bar{k}}{\partial x_{j}}=\delta_{i 3} \frac{g}{\overline{\theta_{v}}}\left(\overline{u_{i}{ }^{\prime} \theta_{v}{ }^{\prime}}\right)-\overline{u_{i}{ }^{\prime} u_{j}{ }^{\prime}} \frac{\partial \overline{u_{i}}}{\partial x_{j}} \\
& -\frac{\partial\left(\overline{u_{j}^{\prime} k}\right)}{\partial x_{j}}-\frac{1}{\bar{\rho}} \frac{\partial\left(\overline{u_{i}{ }^{\prime} p^{\prime}}\right)}{\partial x_{i}}-\epsilon,
\end{aligned}
$$

where $i$ and $j$ are indices and $\epsilon$ is the viscous dissipation of TKE. For a coordinate system aligned with the mean wind and with $z$ normal to the slope, assuming $\partial / \partial x \approx 0$ except for mean advection and with very weak pressure perturbations in the flow, the TKE budget takes the form (Stull, 1988)

$$
\begin{array}{r}
\frac{\partial \bar{k}}{\partial t}=-\bar{u} \frac{\partial \bar{k}}{\partial x} \quad-\bar{w} \frac{\partial \bar{k}}{\partial z}+\frac{g}{\overline{\theta_{v}}}\left(\overline{w^{\prime} \theta_{v}^{\prime}}\right) \\
\text { I } \quad \text { II } \quad \text { III } \quad \text { IV } \\
-\overline{u^{\prime} w^{\prime}} \frac{\partial \bar{u}}{\partial z}-\frac{\partial\left(\overline{w^{\prime} k}\right)}{\partial z}-\epsilon . \\
\text { V }
\end{array}
$$

Term I in (9) is the storage of TKE, term II describes the horizontal advection of TKE by the mean wind, term III is the advection of TKE normal to the surface, term IV is the buoyancy production or destruction of TKE, term $\mathrm{V}$ represents shear generation of TKE, term VI is the transport of TKE by velocity fluctuations normal to the surface, and term VII is the dissipation rate of TKE. Term VI had to be neglected due to the presence of significant noise in the data, which is expected given that it is a third-order statistical moment. Here, gradients are approximated by forward finite differences. A thorough discussion on the uncertainties in the evaluation of terms of (9) can be found in Nelson et al. (2011). The dissipation rate $\epsilon$ can be estimated with the method described in Kiely et al. (1996), in which

$$
\epsilon \approx a r^{-1} D_{u u}{ }^{3 / 2} \text {, }
$$

where $a$ is an empirical coefficient, $r$ is the lag distance obtained using Taylor's hypothesis, and $D_{u u}$ is the secondorder structure function for horizontal wind velocities. Here we take $r=1 \mathrm{~m}$ to be in the inertial subrange of the ABL (Bou-Zeid et al., 2010), and $a=0.35$ following Stull (1988).
A useful dimensionless parameter is the flux Richardson number $R i_{\mathrm{f}}$ :

$$
R i_{\mathrm{f}}=\frac{g}{\overline{\theta_{\mathrm{v}}}} \overline{w^{\prime} \theta_{\mathrm{v}}^{\prime}} / \overline{u^{\prime} w^{\prime}} \frac{\partial \bar{u}}{\partial z}
$$

which describes the ratio of buoyancy production/destruction to shear production of TKE.

Rapid changes are observed in the TKE budget around the local sunset (Figure 14(a)). The daytime mechanical shear production appears linked with the along-valley circulation. The shear production term decreases to the point where it is practically zero for a $40 \mathrm{~min}$ period prior to the local sunset. During that period, the $\partial \bar{u} / \partial z$ is very small (Figure 10). Although the exact reason for this is unclear, we hypothesize that the daytime upvalley flow is 'impinging' on our experimental site since it is located in a turn of the valley axis (section 3.5). The incoming flow 'hits' the steep slope in a region where winds are well-mixed, resulting in weak shear. Further deployments at this site should help elucidate if the weak daytime mechanical production of turbulence is due to a valley curvature effect.

In contrast to the daytime shear production, the buoyancy term is a rather local term and is governed by the radiation budget at the slope scale. The buoyancy term dominates the TKE budget during the decay of convective turbulence. Indeed, the flux Richardson number is much smaller than -1 for that period (Figure 15), except for a spurious data point during the local sunset due to small fluctuations of the shear term around zero (random flux error; Mahrt and Vickers, 2006). The important role of the buoyancy term supports the TKE decay model developed by Nadeau et al. (2011), in which shear production is neglected during the decay period. However, in this instance, the reduction of the buoyancy flux is not a gradual process taking place over several hours as in Nadeau et al. (2011), but is a rather abrupt event due to the rapidly evolving radiation budget. The outcome is a fast decrease of the TKE (Figure 14(b)).

Both the buoyancy and shear terms are very small during the early evening calm period following the local sunset. This is also when the TKE reaches its lowest level $\left(\bar{k}<0.05 \mathrm{~m}^{2} \mathrm{~s}^{-2}\right)$. Interestingly, the dissipation term is non-zero during that period, suggesting that there could be weak transport of TKE to balance (9). Following the onset of a drainage flow, the shear production term grows, but is insufficient to compensate for the dissipation and buoyancy destruction terms, hence the large residual term. Here we hypothesize that (10) could overestimate the TKE dissipation. The advection of TKE normal to the surface is essentially zero for the entire period of interest, whereas there is a weak horizontal advective flux of TKE in the early nighttime period. About $1.5 \mathrm{~h}$ after the local sunset, the flux Richardson number is relatively constant $\left(R i_{\mathrm{f}} \approx 0.58\right)$ with occasional fluctuations, showing that the night-time atmospheric flow remains turbulent. We should point out that the turbulence measurements are taken in a region with $\partial \bar{u} / \partial z<0$ at night, but inversely $\overline{u^{\prime} w^{\prime}}>0$ so that the shear production term stays positive and dominates the night-time TKE budget. The fact that $\partial \bar{u} / \partial z<0$ at the lowest turbulence measurement level, combined with a zero velocity at the surface, suggests again that we are not capturing the maximum wind speed of the skin flow in spite of the lowest measurement being at $1.5 \mathrm{~m}$ above the slope. 

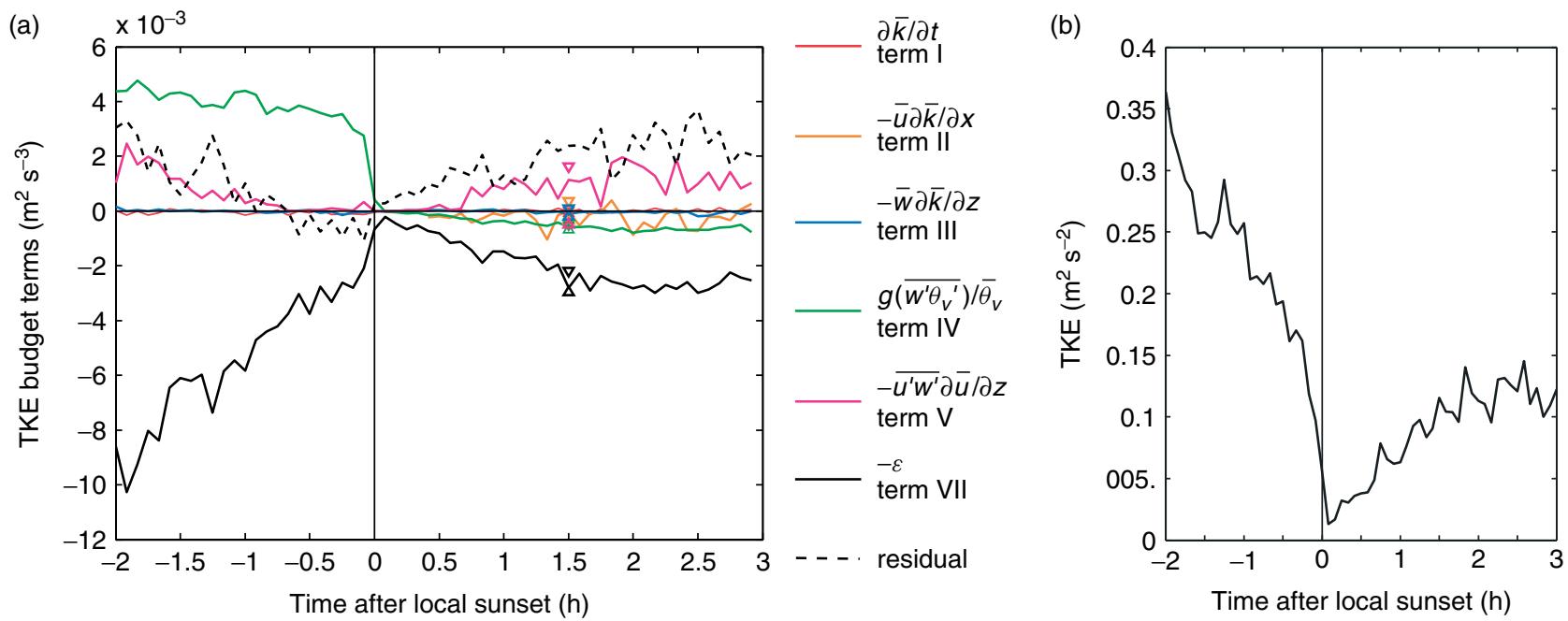

Figure 14. (a) Medians of the storage, advection, buoyancy, shear, dissipation and residual terms of the TKE budget and (b) median of TKE around the local sunset on the nine convective days. Both plots report data collected at the lowest sonic anemometer ( $1.5 \mathrm{~m}$ above the surface) at station T2. The upand down-pointing triangles indicate the interquartile range for each of the terms $1.5 \mathrm{~h}$ after the local sunset.

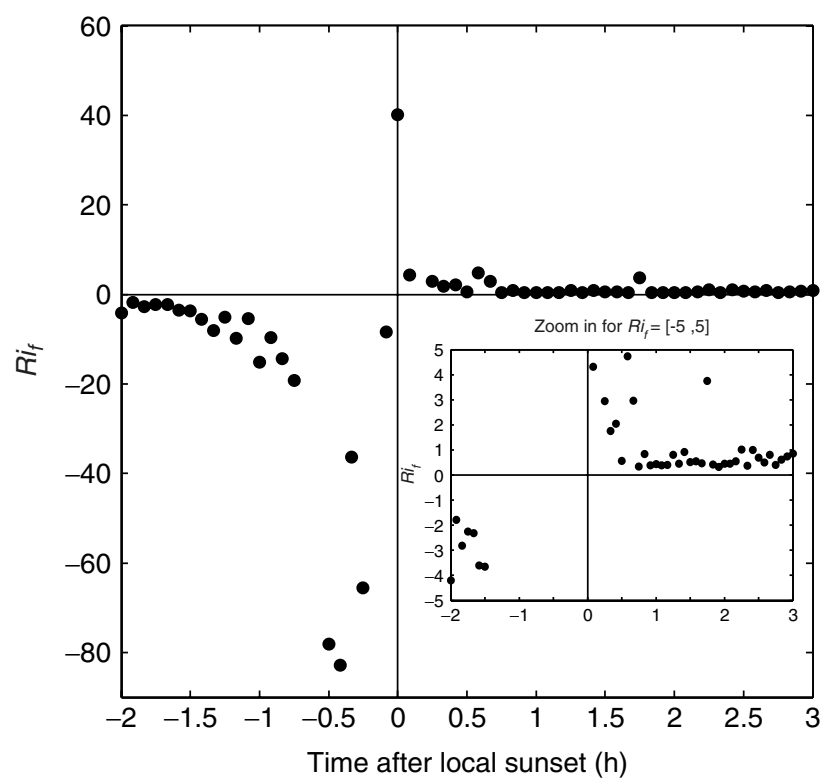

Figure 15. Medians of the flux Richardson number at the lowest sonic anemometer at station $\mathrm{T} 2$ for the nine convective days around the local sunset.

\section{Summary and conclusions}

The results presented in this article are based on a summer field campaign conducted on a steep west-facing slope in the Swiss Alps. The analysis shows that in steep and narrow Alpine valleys and on convective clear-sky days, the timing and dynamics of the evening transition of slope flows is mostly controlled by the local radiation balance. In the evening of sunny days, the topography of the terrain surrounding the slope causes a 'shading front' propagating upslope. The propagation speed of the shading front varies throughout the season due to changes in the apparent trajectory of the sun with respect to the surrounding relief. In response to the observed drop in radiative energy supply at the surface (several hundred $\mathrm{W} \mathrm{m}^{-2}$ within a few minutes), the surface temperature features a nonlinear decrease with two time-scales: a very short one of a few minutes with a decrease of several degrees, and a longer one of a few hours with a gradual reduction of $T_{s}$. The shading front (or local sunset) is followed by the 'early-evening calm' period, previously observed by Acevedo and Fitzjarrald (2001) and Mahrt et al. (2010). This quiescent period is characterized by extremely light winds, variable wind directions and low TKE, all observed in our study. After the local sunset, a stably stratified layer grows above the surface and eventually leads to the formation of a cold layer of air sinking down the slope. This very shallow drainage flow, referred to as a 'skin flow' in previous studies (Manins, 1992; Mahrt et al., 2001), forms locally and displays maximum wind velocities below $1.5 \mathrm{~m}$ above the ground in our case. Regarding the vertical structure of the flow, the convective surface layer winds are well-mixed with the along-valley circulation, while the night-time nearsurface winds display a complex vertical structure, with occasional downvalley flow above the shallow-slope flow layer.

Based on a quantitative analysis of the momentum and thermal equations, we proposed a time-scale describing the slope flow reversal, assuming a balance of inertial and buoyancy forces after the local sunset. We also found that it takes about $1.5 \mathrm{~h}$ for the katabatic flow to reach a quasi-equilibrium after the local sunset, and that radiative flux divergence is expected to play an important role in the early night-time period. The near-surface TKE budget is also highly informative on the slope flow evolution. The mechanical shear production is negligible in the last two hours before the flow transition, in this case possibly because of valley curvature effects. The buoyant production of turbulence dominates the TKE budget during this period and then experiences a sudden decrease exactly at the local sunset. At night, the mechanical production overpowers the buoyant consumption of turbulence by a factor of 1.7. Close to the surface, large gradients of wind velocities normal to the surface are found during the early night.

Previous theoretical and experimental analyses have shown that the slope-flow reversal occurs through a transition front moving from upslope to downslope (Hunt et al., 2003; Brazel et al., 2005; Pardyjak et al., 2009) over gentle slopes. However, this study presents a case where the evening 'transition front' propagates in the other direction 
(from downslope to upslope), suggesting that the physics of the evening transition are fundamentally different over very steep slopes and narrow Alpine valleys in which topographic shading plays a significant role. However further research is needed to fully elucidate the mechanisms related to the transition front. For this purpose, future field campaigns on steep slopes should include a large density of instruments very close to the surface and active profiling of valley crosssections.

This study also describes local shallow drainage flows developing over steep Alpine slopes at night. With these complex circulations, the applicability of traditional surfacelayer scaling under stable conditions is questionable, and new frameworks or formulations might have to be developed.

\section{Acknowledgements}

We are grateful to all our colleagues who helped with the field campaign, including F. Baerenbold, N.C. van de Giesen, J.-D. Perriard, S. Simoni, G. Barrenetxea, M. Diebold, O. Kahler, E. Fortier, M. Calaf, S. Fernandez, I. Bevilacqua, A. Borloz, M. Daniels, C. Fortier, P.-O. Laflamme and T. Mimouni. This field study would not have been possible without the collaborative effort of the Commune d'Orsières. The authors would like to thank Mathias Rotach for his suggestion to use a directional planar fit for post-processing the turbulence data and Holly J. Oldroyd for helpful discussions. This research has been supported by the Swiss National Foundation under grant 200021-120238.

\section{References}

Acevedo OC, Fitzjarrald DR. 2001. The early evening surface-layer transition: Temporal and spatial variability. J. Atmos. Sci. 58: 2650-2667.

Angevine WM, Baltink HK, Bosveld FC. 2001. Observations of the morning transition of the convective boundary layer. Boundary-Layer Meteorol. 101: 209-227.

Baldocchi DD. 2003. Assessing the eddy covariance technique for evaluating carbon dioxide exchange rates of ecosystems: Past, present and future. Glob. Change Biol. 9: 479-492.

Bou-Zeid E, Higgins CW, Huwald H, Meneveau C, Parlange MB. 2010 Field study of the dynamics and modelling of subgrid-scale turbulence in a stable atmospheric surface layer over a glacier. J. Fluid Mech. 665 480-515.

Brazel AJ, Fernando HJS, Hunt JCR, Selover N, Hedquist BC, Pardyjak ER. 2005. Evening transition observations in Phoenix Arizona. J. Appl. Meteorol. 44: 99-112.

Briggs GA. 1981. Canopy effects on predicted drainage flow characteristics and comparisons with observations. In: Preprints Fifth Sympos. on Turbulence, Diffusion and Air Pollution, Atlanta, GA. Amer. Meteorol. Soc: Boston. 113-115.

Brutsaert W. 2005. Hydrology: an introduction. Cambridge University Press: Cambridge, UK.

Burridge DM, Gadd AJ. 1974. 'The Meteorological Office operational 10-level numerical weather prediction model (December 1974)'. Technical Reports 12 and 48, Met Office: Bracknell, UK.

Catalano F, Cenedese A. 2010. High-resolution numerical modeling of thermally driven slope winds in a valley with strong capping. J. Appl. Meteorol. Climatol. 49: 1859-1880.

Christen A, Van Gorsel E, Vogt R, Andretta M, Rotach MW. 2001. 'Ultrasonic anemometer instrumentation at steep slopes: Wind tunnel study - field intercomparison measurements'. MAP Newsletter 15: $164-167$.

Cole GS, Fernando HJS. 1998. Some aspects of the decay of convective turbulence. Fluid Dyn. Res. 23: 161-176.

Colette A, Chow FK, Street RL. 2003. A numerical study of inversionlayer breakup and the effects of topographic shading in idealized valleys. J. Appl. Meteorol. 42: 1255-1272.
Dozier J, Frew J. 1990. Rapid calculation of terrain parameters for radiation modeling from digital elevation data. IEEE Trans. Geosci. Remote Sensing 28: 963-969.

Etzold S, Buchmann N, Eugster W. 2010. Contribution of advection to the carbon budget measured by eddy covariance at a steep mountain slope forest in Switzerland. Biogeosci. 7: 2461-2475.

Fedorovich E, Shapiro A. 2009. Structure of numerically simulated katabatic and anabatic flows along steep slopes. Acta Geophys. 57: 981- 1010 .

Fernando HJS. 2010. Fluid dynamics of urban atmospheres in complex terrain. Ann. Rev. Fluid Mech. 42: 365-389.

Finnigan JJ, Clement R, Malhi Y, Leuning R, Cleugh HA. 2003. A re-evaluation of long-term flux measurement techniques. Part I: Averaging and coordinate rotation. Boundary-Layer Meteorol. 107: $1-48$

Foken T, Wichura B. 1996. Tools for quality assessment of surface-based flux measurements. Agric. Forest Meteorol. 78: 83-105.

Geissbuhler P, Siegwolf R, Eugster W. 2000. Eddy covariance measurements on mountain slopes: The advantage of surface-normal sensor orientation over a vertical set-up. Boundary-Layer Meteorol. 96: $371-392$.

Goulart A, Degrazia G, Rizza U, Anfossi D. 2003. A theoretical model for the study of convective turbulence decay and comparison with large-eddy simulation data. Boundary-Layer Meteorol. 107: 143-155.

Grant ALM. 1997. An observational study of the evening transition boundary layer. Q. J. R. Meteorol. Soc. 123: 657-677.

Grubišić V, Doyle JD, Kuettner J, Mobbs S, Smith RB, Whiteman CD, Dirks R, Czyzyk S, Cohn SA, Vosper S, Weissmann M, Haimov S, De Wekker SFJ, Pan LL, Chow FK. 2008. The terrain-induced rotor experiment - A field campaign overview including observational highlights. Bull. Amer. Meteorol. Soc. 89: 1513-1533.

Hammerle A, Haslwanter A, Schmitt M, Bahn M, Tappeiner U, Cernusca A, Wohlfahrt G. 2007. Eddy covariance measurements of carbon dioxide, latent and sensible energy fluxes above a meadow on a mountain slope. Boundary-Layer Meteorol. 122: 397-416.

Hiller R, Zeeman M, Eugster W. 2008. Eddy-covariance flux measurements in the complex terrain of an alpine valley in Switzerland. Boundary-Layer Meteorol. 127: 449-467.

Hoch SW, Whiteman CD. 2010. Topographic effects on the surface radiation balance in and around Arizona's Meteor Crater. J. Appl. Meteorol. Climatol. 49: 1114-1128.

Hunt JCR, Fernando HJS, Princevac M. 2003. Unsteady thermally driven flows on gentle slopes. J. Atmos. Sci. 60: 2169-2182.

Ingelrest F, Barrenetxea G, Schaefer G, Vetterli M, Couach O, Parlange MB. 2010. Sensorscope: Application-specific sensor network for environmental monitoring. ACM Trans. Sensor Networks 6: 1-32.

Kiely G, Albertson JD, Parlance MB, Eichinger WE. 1996. Convective scaling of the average dissipation rate of temperature variance in the atmospheric surface layer. Boundary-Layer Meteorol. 77: 267-284.

Kleissl J, Honrath RE, Dziobak MP, Tanner D, Martin MV, Owen RC, Helmig D. 2007. Occurrence of upslope flows at the Pico mountaintop observatory: A case study of orographic flows on a small, volcanic island. J. Geophys. Res.-Atmos. 112: D10S35, DOI: 10.1029/2006JD007565.

Kondo J, Sato T. 1988. A simple-model of drainage flow on a slope. Boundary-Layer Meteorol. 43: 103-123.

Kossmann M, Fiedler F. 2000. Diurnal momentum budget analysis of thermally induced slope winds. Meteorol. Atmos. Phys. 75: 195-215.

Kossmann M, Vogtlin R, Corsmeier U, Vogel B, Fiedler F, Binder HJ, Kalthoff N, Beyrich F. 1998. Aspects of the convective boundary-layer structure over complex terrain. Atmos. Environ. 32: 1323-1348.

Lewis HW, Mobbs SD, Lehning M. 2008. Observations of cross-ridge flows across steep terrain. Q. J. R. Meteorol. Soc. 134: 801-816.

Mahrt L. 1998. Stratified atmospheric boundary layers and breakdown of models. Theor. Comput. Fluid Dyn. 11: 263-279.

Mahrt L, Vickers D. 2006. Extremely weak mixing in stable conditions. Boundary-Layer Meteorol. 119: 19-39.

Mahrt L, Richardson S, Seaman N, Stauffer D. 2010. Non-stationary drainage flows and motions in the cold pool. Tellus A 62: 698-705.

Mahrt L, Vickers D, Nakamura R, Soler MR, Sun JL, Burns S, Lenschow DH. 2001. Shallow drainage flows. Boundary-Layer Meteorol. 101: 243-260.

Manins PC. 1992. Vertical fluxes in katabatic flows. Boundary-Layer Meteorol. 60: 169-178.

Manins PC, Sawford BL. 1979. A model of katabatic winds. J. Atmos. Sci. 36: 619-630. 
Matzinger N, Andretta M, Van Gorsel E, Vogt R, Ohmura A, Rotach MW. 2003. Surface radiation budget in an Alpine valley. Q. J. R. Meteorol. Soc. 129: $877-895$.

Nadeau DF, Brutsaert W, Parlange MB, Bou-Zeid E, Barrenetxea G, Couach O, Boldi MO, Selker JS, Vetterli M. 2009. Estimation of urban sensible heat flux using a dense wireless network of observations. Environ. Fluid Mech. 9: 635-653.

Nadeau DF, Pardyjak ER, Higgins CW, Fernando HJS, Parlange MB. 2011. A simple model for the afternoon and early evening decay of convective turbulence over different land surfaces. Boundary-Layer Meteorol. 141: 301-324.

Nappo CJ, Rao KS. 1987. A model study of pure katabatic flows. Tellus A 39: 61-71.

Nelson MA, Pardyjak ER, Klein P. 2011. Momentum and turbulent kinetic energy budgets within the Park Avenue street canyon during the joint urban 2003 field campaign. Boundary-Layer Meteorol. 140: $143-162$.

Nieuwstadt FTM, Brost RA. 1986. The decay of convective turbulence. J. Atmos. Sci. 43: 532-546.

Oliphant AJ, Spronken-Smith RA, Sturman AP, Owens IF. 2003. Spatial variability of surface radiation fluxes in mountainous terrain. J. Appl. Meteorol. 42: 113-128.

Oncley SP, Friehe CA, Larue JC, Businger JA, Itsweire EC, Chang SS. 1996. Surface-layer fluxes, profiles, and turbulence measurements over uniform terrain under near-neutral conditions. J. Atmos. Sci. 53: 1029-1044.

Papadopoulos KH, Helmis CG. 1999. Evening and morning transition of katabatic flows. Boundary-Layer Meteorol. 92: 195-227.

Papadopoulos KH, Helmis CG, Soilemes AT, Kalogiros J, Papageorgas PG, Asimakopoulos DN. 1997. The structure of katabatic flows down a simple slope. Q. J. R. Meteorol. Soc. 123: 1581-1601.

Pardyjak ER, Fernando HJS, Hunt JCR, Grachev AA, Anderson J. 2009. A case study of the development of nocturnal slope flows in a wide open valley and associated air quality implications. Meteorol. Z. 18: 85-100.

Pino D, Jonker HJJ, de Arellano JVG, Dosio A. 2006. Role of shear and the inversion strength during sunset turbulence over land: Characteristic length scales. Boundary-Layer Meteorol. 121: 537-556.

Princevac M, Hunt JCR, Fernando HJS. 2008. Quasi-steady katabatic winds on slopes in wide valleys: Hydraulic theory and observations. J. Atmos. Sci. 65: 627-643.

Rotach MW, Zardi D. 2007. On the boundary-layer structure over highly complex terrain: Key findings from MAP. Q. J. R. Meteorol. Soc. 133: 937-948.

Rotach MW, Andretta M, Calanca P, Weigel AP, Weiss A. 2008. Boundary-layer characteristics and turbulent exchange mechanisms in highly complex terrain. Acta Geophys. 56: 194-219.

Rotach MW, Calanca P, Graziani G, Gurtz J, Steyn DG, Vogt R, Andretta M, Christen A, Cieslik S, Connolly R, De Wekker SFJ, Galmarini S, Kadygrov EN, Kadygrov V, Miller E, Neininger B, Rucker M, Van Gorsel E, Weber H, Weiss A, Zappa M. 2004. Turbulence structure and exchange processes in an alpine valley - The Riviera project. Bull. Amer. Meteorol. Soc. 85: 1367-1385.
Schumann U. 1990. Large-eddy simulation of the up-slope boundarylayer. Q. J. R. Meteorol. Soc. 116: 637-670.

Serafin S, Zardi D. 2010a.. Daytime heat transfer processes related to slope flows and turbulent convection in an idealized mountain valley. J. Atmos. Sci. 67: 3739-3756.

Serafin S, Zardi D. 2010b.. Structure of the atmospheric boundary layer in the vicinity of a developing upslope flow system: A numerical model study. J. Atmos. Sci. 67: 1171-1185.

Shapiro A, Fedorovich E. 2007. Katabatic flow along a differentially cooled sloping surface. J. Fluid Mech. 571: 149-175.

Simoni S, Padoan S, Nadeau DF, Diebold M, Porporato A, Barrenetxea G, Ingelrest F, Vetterli M, Parlange MB. 2011. Hydrologic response of an Alpine watershed: Application of a meteorological wireless sensor network to understand streamflow generation. Water Resources Res. 47: W10524, DOI: 10.1029/2011wr010730.

Skyllingstad ED. 2003. Large-eddy simulation of katabatic flows. Boundary-Layer Meteorol. 106: 217-243.

Smith CM, Skyllingstad ED. 2005. Numerical simulation of katabatic flow with changing slope angle. Mon. Weather Rev. 133: 3065-3080.

Sorbjan Z. 1997. Decay of convective turbulence revisited. BoundaryLayer Meteorol. 82: 501-515.

Stull RB. 1988. An introduction to boundary-layer meteorology. Kluwer Academic Publishers: Dordrecht, The Netherlands.

Trachte K, Nauss T, Bendix J. 2010. The impact of different terrain configurations on the formation and dynamics of katabatic flows: Idealised case studies. Boundary-Layer Meteorol. 134: 307-325.

Van Gorsel E, Christen A, Feigenwinter C, Parlow E, Vogt R. 2003. Daytime turbulence statistics above a steep forested slope. BoundaryLayer Meteorol. 109: 311-329.

Weigel AP, Rotach MW. 2004. Flow structure and turbulence characteristics of the daytime atmosphere in a steep and narrow Alpine valley. Q. J. R. Meteorol. Soc. 130: 2605-2627.

Whiteman CD. 1990. Observations of thermally developed wind systems in mountainous terrain. In: Atmospheric Processes over Complex Terrain, Meteorol. Monogr. 23: Blumen W. (ed.) Amer. Meteorological Soc: Boston. 5-42.

Whiteman CD. 2000. Mountain meteorology: Fundamentals and applications. Oxford University Press: New York.

Whiteman CD, Allwine KJ. 1986. Extraterrestrial solar radiation on inclined surfaces. Environ. Softw. 1: 164-169.

Whiteman CD, Doran JC. 1993. The relationship between overlying synoptic-scale flows and winds within a valley. J. Appl. Meteorol. 32: 1669-1682.

Whiteman CD, Allwine KJ, Fritschen LJ, Orgill MM, Simpson JR. 1989. Deep valley radiation and surface-energy budget microclimates. Part I: Radiation. J. Appl. Meteorol. 28: 414-426.

Whiteman CD, Muschinski A, Zhong S, Fritts D, Hoch SW, Hahnenberger M, Yao WQ, Hohreiter V, Behn M, Cheon Y, Clements CB, Horst TW, Brown WOJ, Oncley SP. 2008. METCRAX 2006; Meteorological experiments in Arizona's Meteor Crater. Bull. Amer. Meteorol. Soc. 89: 1665-1680.

Wilczak J, Oncley S, Stage S. 2001. Sonic anemometer tilt correction algorithms. Boundary-Layer Meteorol. 99: 127-150. 